\title{
Impaired $\theta-\gamma$ Coupling Indicates Inhibitory Dysfunction and Seizure Risk in a Dravet Syndrome Mouse Model
}

 \\ Rob A. Voskuyl, ${ }^{1}{ }^{\circledR}$ Roland D. Thijs, ${ }^{3,4}{ }^{\circledR}$ Ghanim Ullah, ${ }^{2}{ }^{\circledR}$ Arn M.J.M. van den Maagdenberg, ${ }^{1,3 *}$ and \\ (1) Else A. Tolner ${ }^{1,3 *}$ \\ ${ }^{1}$ Department of Human Genetics, Leiden University Medical Center, 2300 RC Leiden, The Netherlands, ${ }^{2}$ Department of Physics, University of South \\ Florida, Tampa, Florida 33620, ${ }^{3}$ Department of Neurology, Leiden University Medical Center, 2300 RC Leiden, The Netherlands, and ${ }^{4}$ Stichting \\ Epilepsie Instellingen Nederland, 2103 SW Heemstede, The Netherlands
}

Dravet syndrome (DS) is an epileptic encephalopathy that still lacks biomarkers for epileptogenesis and its treatment. Dysfunction of $\mathrm{Na}_{\mathrm{V}} 1.1$ sodium channels, which are chiefly expressed in inhibitory interneurons, explains the epileptic phenotype. Understanding the network effects of these cellular deficits may help predict epileptogenesis. Here, we studied $\theta-\gamma$ coupling as a potential marker for altered inhibitory functioning and epileptogenesis in a DS mouse model. We found that cortical $\theta-\gamma$ coupling was reduced in both male and female juvenile DS mice and persisted only if spontaneous seizures occurred. $\theta-\gamma$ Coupling was partly restored by cannabidiol (CBD). Locally disrupting $\mathrm{Na}_{\mathrm{v}} 1.1$ expression in the hippocampus or cortex yielded early attenuation of $\theta-\gamma$ coupling, which in the hippocampus associated with fast ripples, and which was replicated in a computational model when voltage-gated sodium currents were impaired in basket cells (BCs). Our results indicate attenuated $\theta-\gamma$ coupling as a promising early indicator of inhibitory dysfunction and seizure risk in DS.

Key words: Dravet syndrome; epilepsy; interneurons; Nav1.1; sodium channels

Significance Statement

Biomarkers for Dravet syndrome (DS), a severe type of childhood epilepsy, are currently not available. Despite advances in our understanding of the cellular pathophysiology of DS, the effects on brain network dynamics largely remain to be uncovered. In the present work we show that decreased $\theta-\gamma$ coupling precedes and associates with seizure activity in a DS mouse model, which could be replicated by brain region-specific ablation of $\mathrm{Na}_{\mathrm{v}} 1.1$, a sodium channel affected in the majority of DS patients. Computational modeling of sodium channel dysfunction in inhibitory interneurons yielded a similar decrease in $\theta-\gamma$ coupling. Together, these results suggest that impaired $\theta-\gamma$ coupling is a promising early indicator of inhibitory dysfunction and seizure risk in DS.

\section{Introduction}

Dravet syndrome (DS) is an epileptic encephalopathy characterized by early-onset seizures, followed by severe cognitive and behavioral deficits (Wolff et al., 2006; Dravet, 2011). The majority of DS cases result from a heterozygous loss-of-function mutation in the SCN1A gene, which encodes the pore-forming $\alpha 1$ subunit of voltage-gated sodium channel type $1\left(\mathrm{Na}_{\mathrm{v}} 1.1\right)$. In mice with a

Received Aug. 13, 2020; revised 0ct. 2, 2020; accepted Nov. 12, 2020.

Author contributions: N.A.J., C.P., and G.U. designed research; N.A.J., M.S., and A.D. performed research; N.A.J., C.P., A.W.v.B., R.A.V., and G.U. analyzed data; N.A.J. wrote the paper. N.A.J., R.D.T., G.U., A.M.J.M.v.d.M. and E.A.T. edited the paper.

*A.M.J.M.v.d.M. and E.A.T. contributed equally to this work.

This work was supported by the Dutch National Epilepsy Foundation Grant 2017-10, Medical NeuroDelta, and the National Institutes of Health Grant R01AG053988.

The authors declare no competing financial interests.

Correspondence should be addressed to Nico A. Jansen at n.a.jansen@lumc.nl.

https://doi.org/10.1523/JNEUROSCI.2132-20.2020

Copyright $\odot 2021$ the authors heterozygous knock-out of Scn1a, core clinical features of DS including spontaneous seizures (Yu et al., 2006), cognitive deficits and autism-related behavior (Han et al., 2012) are replicated. Voltage-dependent sodium currents are reduced in GABAergic inhibitory interneurons, while unaffected in hippocampal pyramidal (EX) neurons of DS mice (Yu et al., 2006). In the hippocampus and cortex, $\mathrm{Na}_{\mathrm{V}} 1.1$ is mostly expressed in interneurons (Ogiwara et al., 2007) and loss of $\mathrm{Na}_{\mathrm{V}} 1.1$ function in inhibitory populations is sufficient to reproduce the epileptic phenotype of DS mice (Cheah et al., 2012). These studies thus implicate loss of inhibitory functioning in DS pathophysiology.

How loss of $\mathrm{Na}_{\mathrm{V}} 1.1$ function affects network dynamics, however, remains unclear, while such knowledge is crucial to understanding epileptogenesis and cognitive deficits. Although excitability of cortical inhibitory interneurons was decreased in brain slices of DS mice, in vivo cortical local field potential (LFP) and spontaneous interneuron firing appeared unaffected (De Stasi et al., 2016). Fast-spiking parvalbumin-positive interneurons, a class of 
inhibitory interneurons that is affected in DS mice (Tai et al., 2014; De Stasi et al., 2016), importantly contribute to LFP $\gamma$ oscillations (Freund and Katona, 2007; Buzsáki and Wang, 2012). Parvalbuminergic neurons show a particularly high propensity to fire phase-locked to $\theta$ oscillations in the hippocampus (Csicsvari et al., 1999) and cortex (Sirota et al., 2008), suggesting a key role of these interneurons in $\theta-\gamma$ cross-frequency coupling (Buzsáki and Wang, 2012). Coupling of $\gamma$ oscillations to $\theta$ rhythm is indeed decreased when synaptic inhibition onto parvalbumin-positive neurons is impaired (Wulff et al., 2009). Recently, local loss of hippocampal $\mathrm{Na}_{\mathrm{V}} 1.1$ function was shown to impair inhibitory firing and coupling of $\gamma$ amplitude to $\theta$ phase in rats (Sakkaki et al., 2020). How this relates to seizure development, hippocampal and cortical dynamics in DS mice, however, remains to be explored.

Here, we studied spontaneous cortical network dynamics during development in DS mice for early changes in $\theta$ or $\gamma$ oscillations and their cross-frequency phase-amplitude coupling. By inducing local heterozygous or homozygous knock-out of Scn1a in the hippocampus or cortex, we addressed the effect of partial or total ablation of $\mathrm{Na}_{\mathrm{V}} 1.1$, respectively, within these structures on network dynamics in relation to seizure development. We found that $\theta-\gamma$ coupling was decreased in DS mice compared with wild-type (WT), which, also upon local ablation of $\mathrm{Na}_{\mathrm{V}} 1.1$, preceded seizure activity. Decreased $\theta-\gamma$ coupling persisted only in animals with spontaneous seizures, and associated with hippocampal fast ripples. In a computational hippocampal network model, loss of voltage-gated sodium currents in inhibitory neurons reproduced the main experimental findings, including a pronounced impairment of $\theta-\gamma$ coupling. These results suggest that $\theta-\gamma$ coupling may serve as an early indicator of inhibitory dysfunction and seizure risk in DS.

\section{Materials and Methods \\ Animals}

Mice with a deletion of exon 8 of the Scnla gene were created as described previously (Jansen et al., 2020). These global Scnl $1 a^{-/+}$mice (referred to as "DS mice") were backcrossed to C57BL/6J mice for at least five generations. Both male and female DS mice and WT littermates were used for experiments. In the conditional Scnla mouse line, exon 8 of the Scn1a gene is flanked by LoxP sites (Jansen et al., 2020), which allows for region-specific ablation after exposure to Cre recombinase. Heterozygous and homozygous floxed $\left(S c n 1 a^{\mathrm{fl} /+}\right.$ or $S c n 1 a^{\mathrm{f} / / \mathrm{l} l}$, respectively) mice and WT littermates were used for the viral injection experiments. Animals had free access to food and water and were kept under standard housing conditions (temperature of $22 \pm 1.5^{\circ} \mathrm{C}, 12 / 12 \mathrm{~h}$ light/ dark cycle). All experiments were approved by local and national ethical committees following recommendations of the European Communities Council Directive (2010/63/EU) and conducted in accordance with ARRIVE guidelines.

\section{Surgery and viral infection}

For chronic recordings in DS mice and WT littermates, LFP electrodes (75- $\mu \mathrm{m}$ platinum/iridium; PT6718, Advent Research Materials) were implanted at P20-P21 under isoflurane anesthesia (induction 4\%; maintenance $1.5 \%)$. Electrodes were implanted in primary visual cortex [V1; $-3.5 \mathrm{~mm}$ anteroposterior (AP), $\pm 2.4 \mathrm{~mm}$ mediolateral (ML), and -0.5 $\mathrm{mm}$ dorsoventral (DV) relative to bregma] and primary motor cortex $(\mathrm{M} 1 ;+1.5 \mathrm{~mm} \mathrm{AP}, \pm 1.8 \mathrm{~mm} \mathrm{ML},-0.5 \mathrm{~mm} \mathrm{DV})$. A subset of WT and DS mice was implanted with an additional LFP electrode in the right dorsal hippocampus ( $-2.0 \mathrm{~mm} \mathrm{AP},+2.2 \mathrm{~mm} \mathrm{ML},-1.4 \mathrm{~mm} \mathrm{DV})$.

To induce local knock-out of Scnla, an AAV vector expressing mCherry-Cre under the EF1 $\alpha$-promotor (viral prep \# 55632, a gift from Karl Deisseroth, Addgene) was injected in postnatal day (P)42-P56 $\operatorname{Scn} 1 a^{\mathrm{f} /+}$ and $\operatorname{Scn} 1 a^{\mathrm{f} / \mathrm{fl}}$ mice. Injections ( $500 \mathrm{nl}$ per injection, $50 \mathrm{nl} / \mathrm{min}$ ) were made bilaterally in dorsal $(-2.0 \mathrm{~mm} \mathrm{AP}, \pm 2.2 \mathrm{~mm} \mathrm{ML},-1.4 \mathrm{~mm}$ $\mathrm{DV})$ and ventral $(-3.0 \mathrm{~mm} \mathrm{AP,} \pm 3.1 \mathrm{~mm} \mathrm{ML},-2.6 \mathrm{~mm} \mathrm{DV})$ hippocampus, or in V1, followed by implantation of LFP electrodes. For cortically injected animals, LFP electrodes were implanted in V1 and M1. The use of heterozygous and homozygous floxed mice was predicted to result in a partial and total ablation of $\mathrm{Na}_{\mathrm{V}} 1.1$ following local expression of Cre, respectively. WT littermates that underwent the same procedure served as controls. For cortical injections, in a subset of Scn $1 a^{\mathrm{fl} /+}$ mice, a different AAV vector was used (expressing eGFP-Cre; viral prep \#105545, a gift from James M. Wilson, Addgene) to allow comparison with previously published data (Jansen et al., 2020).

\section{Pharmacology}

Cannabidiol (CBD; Tocris) was dissolved in DMSO, which was diluted in a vehicle solution (5\% DMSO: $5 \%$ cremophor: $90 \%$ saline) immediately before injection. P35-P36 DS mice received an intraperitoneal injection of CBD (100 mg/kg body weight) or vehicle on two consecutive days between 8 and 10 A.M., in a randomized fashion and by an experimenter blinded to the treatment.

\section{Immunohistochemistry}

After experiments, animals were euthanized by $\mathrm{CO}_{2}$ and transcardially perfused with PBS and $4 \%$ paraformaldehyde. Following removal and postfixation of brain tissue, coronal sections $(20 \mu \mathrm{m})$ were prepared. Sections were heated in $10 \mathrm{mmol} / \mathrm{l}$ sodium citrate buffer with $0.05 \%$ Tween for $10 \mathrm{~min}$ at $80^{\circ} \mathrm{C}$. Subsequently, a blocking solution containing $10 \%$ normal goat serum was applied, and sections were incubated in rabbit anti-Na 1.1 (1:200; Alomone Labs), followed by incubation in goat anti-rabbit Cy2 (1:200; Jackson ImmunoResearch). Mounting was performed in glycerol/PBS (1:1) containing $12.5 \mathrm{mg} / \mathrm{ml}$ sodium azide and $1 \mu \mathrm{l} / \mathrm{ml}$ Hoechst-33258. Sections were examined using an epifluorescence or confocal microscope with appropriate filter sets.

\section{Data acquisition and analysis}

DS mice and WT littermates were videotaped from P18 to P19 in a PhenoTyper home cage (Noldus) to allow detection of early spontaneous seizures, until the day of surgery at P20-P21. Immediately after surgery, both these mice and virally injected mice were connected to a seven-channel commutator in a Faraday cage for continuous recordings of LFP and video. Signals were preamplified $(3 \times)$, filtered $(0.05-500 \mathrm{~Hz})$, and amplified $(200 \times$ and $400 \times$ for hippocampal and cortical recordings, respectively) using custom-build hardware, and digitized at $5 \mathrm{kHz}$ (Power 1401 and Spike2 software, CED). All LFP recordings were post hoc inspected for epileptiform activity. The Racine scale (Racine, 1972) was used for scoring of behavior from video recordings during discharges that lasted $>5$ s. Seizures that progressed to stage 3-5 were included in analyses, as these seizures could also be reliably detected when only video recordings were available (i.e., for P18-P21 mice). For detection of interictal spikes (IISs) following local knock-out of Scn1a, local LFP power in the 30- to $100-\mathrm{Hz}$ range was calculated every $24 \mathrm{~h}$ for $1 \mathrm{~h}$ of non-REM sleep, a vigilance state during which IIS are prevalent in DS mice (Kalume et al., 2015). Candidate events exceeding a threshold of three SDs of signal were visually inspected, and animals were considered showing IIS if more than five IIS were observed during the analyzed $1-\mathrm{h}$ window on that day. To detect fast ripples, hippocampal LFP recordings were bandpass filtered (infinite impulse response Butterworth filter of second order) between 200 and $600 \mathrm{~Hz}$ and candidate events were detected by thresholding $(>10$ SDs), which effectively distinguished fast ripples from IIS. Only events that occurred during behavioral immobility, assessed from the reference signal and locomotor activity recorded by an infrared motion detection sensor in the Faraday cage, were visually inspected, as muscle artifacts were often found in the $200-$ to $600-\mathrm{Hz}$ frequency range during active wakefulness.

To assess cortical network dynamics during REM sleep and active wakefulness, LFP recorded during the morning (6-12 A.M.) was analyzed, starting at P23, allowing 2-3d of habituation to the recording setup. Vigilance state was determined per 5-s epoch using V1 LFP, the reference signal and locomotor activity recorded by the infrared motion detection sensor. Epochs during seizures and/or postictal periods (1 h after the end of a seizure) were excluded from further analyses. REM sleep was defined by a $\theta(5-10 \mathrm{~Hz})$ to $\delta(1-4 \mathrm{~Hz})$ power ratio of $>2.5$, in the absence of locomotor activity or motion artifacts. Active wakefulness was defined by a $\theta-\delta$ power ratio of $>2$ during epochs containing 
locomotor activity and/or high variance in the reference signal. Epochs were artifact-rejected, low-pass-filtered (Chebyshev IIR eighth-order filter) and down-sampled to $1 \mathrm{kHz}$. A total of $10 \mathrm{~min}$ of randomly selected epochs was used for further analyses. Power spectra were computed by applying a Hamming window over each epoch, followed by a fast Fourier transform and averaging of the resulting power spectra. Phase-amplitude coupling was assessed using a measure referred to as the modulation index (MI), calculated as described previously (Tort et al., 2010). In short, LFP epochs were bandpass-filtered for phase (3-14 Hz, 2- Hz bandwidths, steps of $1 \mathrm{~Hz}$ ) and amplitude $(40-200$ or $40-300 \mathrm{~Hz}, 4-\mathrm{Hz}$ bandwidths, steps of $2 \mathrm{~Hz}$ ) frequencies. The Hilbert transform was applied to extract phase and amplitude information. Each phase frequency was binned in 18 bins of $20^{\circ}$, and mean amplitude per amplitude frequency was calculated inside each bin. A distribution was subsequently obtained by normalization of the mean amplitude in each phase bin by the sum over all bins. To compare the resulting phase-amplitude distribution with a uniform distribution, the Kullback-Leibler distance was calculated. The MI was obtained by normalizing this metric to the logarithm of the number of phase bins. For group analyses, $\theta-\gamma$ coupling was expressed in a single value by averaging over all $\theta$ and $\gamma$ frequencies, or over specific $\gamma$ bands, as indicated. All analyses were performed using custom-written MATLAB (versions used: 2018b and 2019b, MathWorks) scripts.

\section{Computer modeling}

The basic equations for the membrane potential of individual neurons and various ion channels were adopted from (Kopell et al., 2010). The model network consists of five excitatory (EX) neurons, five oriens-lacunosum moleculare (OLM) interneurons, and five fast-spiking basket cell (BC) interneurons, with all-to-all connections. We noticed that increasing the network size did not change the conclusions from the model as long as the synaptic connections were properly scaled (data not shown). The equations for individual cells were modified and extended to incorporate the dynamics of various ion species in the intracellular and extracellular spaces of the neurons and neurotransmitter homeostasis using a formalism previously developed (Cressman et al., 2009; Hübel et al., 2017; Ullah, 2019). Full details about the model are given in Extended Data Fig. 10-1. Here, we describe the main equations.

The membrane potential, $V_{m}$, of each EX, BC, and OLM neuron in the network is controlled by various $\mathrm{Na}^{+}\left(I_{N a}\right), \mathrm{K}^{+}\left(I_{K}\right)$, and $\mathrm{Cl}^{-}\left(I_{C l}\right)$ currents, $\mathrm{Na}^{+}$and $\mathrm{K}^{+}$currents because of the $\mathrm{Na}^{+} / \mathrm{K}^{+}$-ATPase $\left(I_{\text {pump }}\right)$, and random inputs from neurons that were not a part of the network, modeled as a Gaussian distribution $\left(I_{\text {stoch }}\right)$, that is,

$$
C_{m} \frac{d V_{m}^{E X, B C, O L M}}{d t}=I_{N a}^{E X, B C, O L M}+I_{K}^{E X, B C, O L M}+I_{C l}^{E X, B C, O L M}+I_{s t o c h}^{E X, B C, O L M},
$$

where $\mathrm{C}_{m}$ is the membrane capacitance and superscripts $E X, B C$, and OLM correspond to EX, BC, and OLM neurons, respectively. Various currents used for the different neuron types are given in the section Extended Data Fig. 10-1, membrane potential.

To model the dynamics of various ionic species, we considered the extracellular space (ECS) as a separate compartment surrounding each cell. Each neuron exchanged ions with its ECS compartment through active and passive currents, and the $\mathrm{Na}^{+} / \mathrm{K}^{+}$-ATPase. The ECS compartment can also exchange $\mathrm{K}^{+}$with the glial compartment, and perfusion solution (or vasculature in intact brain; Cressman et al., 2009; Ullah and Schiff, 2010; Wei et al., 2014; Ullah et al., 2015). Including diffusion of ions between the ECS compartments of neighboring neurons did not affect the results and was therefore ignored.

The change in extracellular $\mathrm{K}^{+}$concentration $\left(\left[\mathrm{K}^{+}\right]_{o}\right)$ is a function of $I_{K}, I_{\text {pump }}$, uptake by glia surrounding the neuron $\left(I_{\text {glia }}\right)$, and the diffusion between the neuron and bath perfusate $\left(I_{\text {diff }}\right)$.

$$
\frac{d\left[K^{+}\right]_{o}}{d t}=-\gamma \beta I_{K}-2 \gamma \beta I_{\text {pump }}+I_{\text {glia }}-I_{\text {diff }}
$$

Where $\beta$ is the ratio of intracellular space (ICS) to ECS. $\gamma=A_{m}^{(n)} \times 10^{4} /\left(F \times \omega_{i}\right)$ is the conversion factor from current units to flux units. $F, A_{m}^{(n)}$, and $\omega_{i}$ are the Faraday's constant, surface area of the neuron, and intracellular volume of the neuron, respectively. The factor 2 in front of $I_{\text {pump }}$ is because of the fact that the $\mathrm{Na}^{+} / \mathrm{K}^{+}$pump extrudes two $\mathrm{K}^{+}$in exchange for three $\mathrm{Na}^{+}$ions.

The rate of change of intracellular $\mathrm{Na}^{+}$concentration $\left(\left[\mathrm{Na}^{+}\right]_{i}\right)$ is controlled by $I_{N a}$ and $I_{\text {pump }}$ (Cressman et al., 2009), that is,

$$
\frac{d\left[N a^{+}\right]_{i}}{d t}=-\gamma I_{N a}-3 \gamma I_{p u m p}
$$

The fluxes used in Equations 2, 3 are listed in Extended Data Fig. $10-1$, ion concentrations. The concentrations of intracellular $\mathrm{K}^{+}\left(\left[\mathrm{K}^{+}\right]_{i}\right)$, intracellular $\mathrm{Cl}^{-}\left(\left[\mathrm{Cl}^{-}\right]_{i}\right)$, extracellular $\mathrm{Na}^{+}\left(\left[\mathrm{Na}^{+}\right]_{o}\right)$, and extracellular $\mathrm{Cl}^{-}\left(\left[\mathrm{Cl}^{-}\right]_{0}\right)$ are given by conservation laws and are also listed in the same section.

In addition to ion concentration dynamics, our model also incorporates the details of neurotransmitter homeostasis. Glutamate and GABA in the synaptic cleft and ECS are regulated by (1) spiking-related release from EX (for glutamate), BC and OLM (for GABA), (2) uptake by presynaptic and postsynaptic neurons and glia through glutamate and GABA transporters, (3) diffusion between the cleft and ECS, and (4) the recycling into releasable pools. The model also includes the binding and unbinding of glutamate to NMDA and AMPA receptors, and $\mathrm{GABA}$ to $\mathrm{GABA}_{\mathrm{A}}$ receptors, and the currents because of these receptors. Details of the equations are given in Extended Data Fig. 10-1, neurotransmission.

The LFP is modeled by considering a non-spiking EX neuron in the network as described previously (Kopell et al., 2010). This neuron receives the same synaptic inputs as the active EX neurons in the network, but it does not generate action potentials because of the absence of the main currents responsible for action potential generation. The model LFP thus reflects subthreshold voltage changes in the EX-cell population. Similar to the in vivo data analysis, $10 \mathrm{~min}$ of simulated LFP data were used to obtain power spectra and phase-amplitude coupling metrics, as described earlier.

\section{Experimental design and statistical analysis}

Data from 89 mice were included, including 15 WT and 26 DS mice for video-EEG recordings, nine DS mice for pharmacological experiments, and $13 \mathrm{WT}, 14 S_{c n 1} a^{\mathrm{fl} /+}$, and $12 S_{c n 1} a^{\mathrm{fl} / \mathrm{fl}}$ mice for AAV vector injections. Data are presented as mean \pm SEM, unless indicated otherwise. Statistical testing was conducted in MATLAB or GraphPad Prism (GraphPad Software). Based on whether data were paired and their distribution normality, which was assessed by the Anderson-Darling test, data were compared using the Welch's $t$ test, paired $t$ test, MannWhitney test, or Wilcoxon test for single comparisons. For multiple comparisons, a one or two-way ANOVA with Tukey's test, repeatedmeasures ANOVA with Dunnett's test or Kruskal-Wallis with Dunn's test was used. Sample sizes were not based on statistical methods, but instead informed by those frequently used in the field; $p<0.05$ was considered to indicate significance.

\section{Results}

\section{Modulation of cortical $\gamma$ amplitude by $\theta$ phase is attenuated in juvenile DS mice}

Cortical LFP and video were recorded in freely behaving Scn1 $1 a^{-/+}$ (DS) and WT mice starting from P20-P21. Modulation of cortical $\gamma$ oscillations by $\theta$ rhythm is low during vigilance states lacking prominent $\theta$ oscillations, i.e., during quiet wakefulness and non-REM sleep (Scheffzük et al., 2011). We therefore limited our analyses to epochs during vigilance states with prominent cortical $\theta$ oscillations, i.e., REM sleep (examples in Fig. 1A) and active wakefulness. Average V1 LFP power spectral density for $\theta$ (5$10 \mathrm{~Hz})$, low $\gamma(40-90 \mathrm{~Hz})$, and high $\gamma(90-160 \mathrm{~Hz})$ frequencies during REM sleep at P23 was similar between genotypes (Fig. $1 B, C)$, although a decrease in $\theta$ peak frequency was observed in DS mice (Fig. 1D). Comodulogram analyses of V1 LFP in 
A

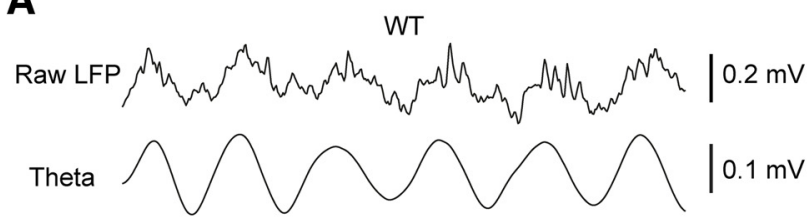

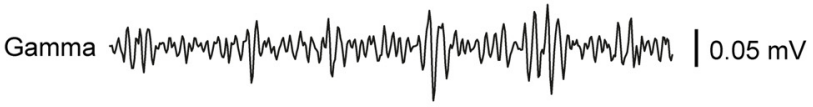

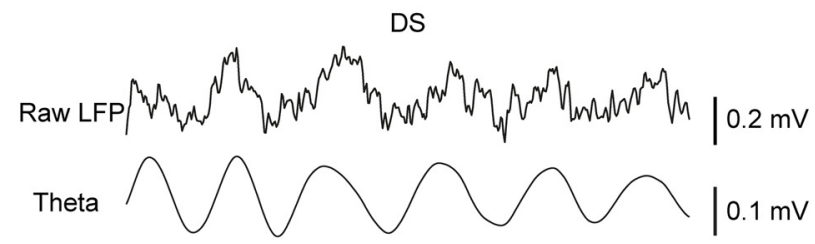

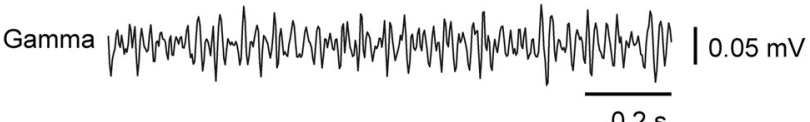
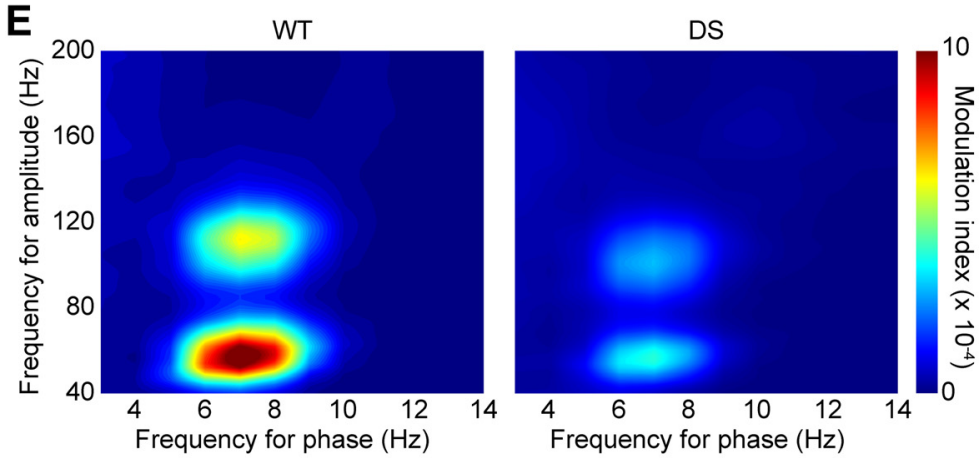

G

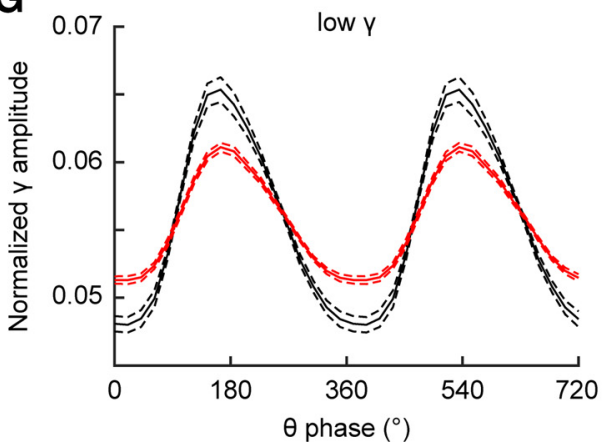

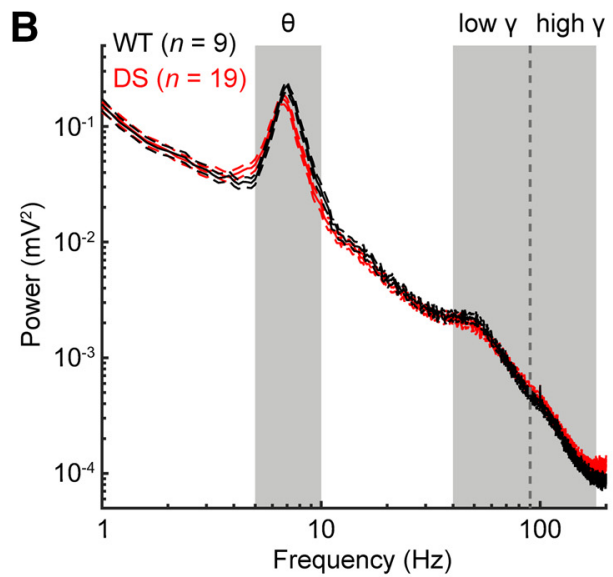

D

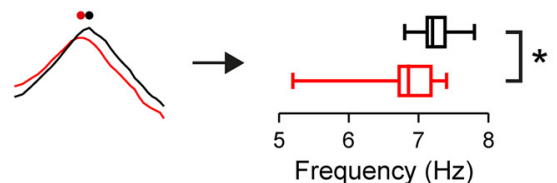

C
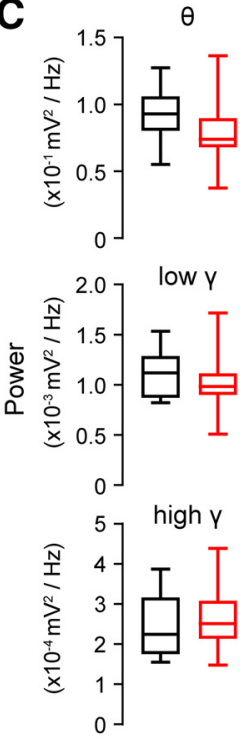

$\mathbf{F}$

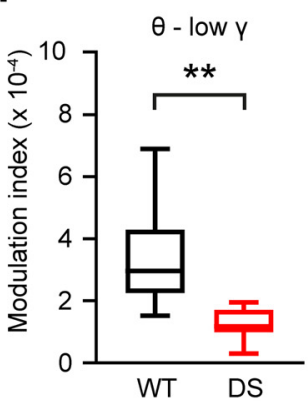

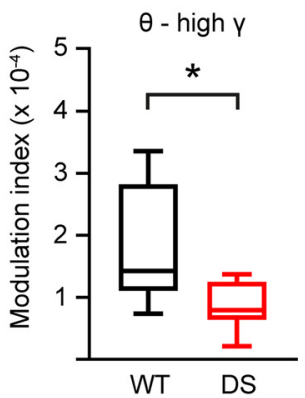

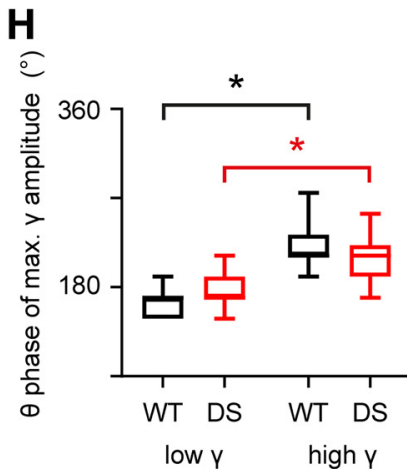

Figure 1. DS mice display decreased cortical $\theta-\gamma$ cross-frequency coupling at P23. $\boldsymbol{A}$, Example traces of raw, $\theta$-filtered (5-10 Hz) and $\gamma$-filtered (40-160 Hz) LFP in the V1 during REM sleep in a WT and DS mouse. B, Average V1 LFP power spectra during REM sleep in WT (black) and DS (red) mice. C, No significant differences in power were present between genotypes within $\theta$, low $(40-90 \mathrm{~Hz})$ or high $\gamma(90-160 \mathrm{~Hz})$ frequency ranges. Peak $\theta$ frequency was significantly reduced in $\mathrm{DS}$ mice $(\boldsymbol{D}$; detail of mean power in $\theta$ range, black and red dots indicate average peak $\theta$ frequency; $t_{(27)}=2.5, * p=0.020$, Welch's $t$ test). $\boldsymbol{E}$, Average phase-amplitude comodulograms of V1 during REM sleep in WT $(n=9)$ and DS $(n=19)$ mice at P23. $\boldsymbol{F}, \theta$ - $\gamma$ Coupling was significantly reduced in DS mice, for both low and high $\gamma$ frequencies $\left(t_{(8.9)}=3.8\right.$ and $t_{(9.2)}=2.9$, respectively, $* p=0.019$ and $* * p=0.004$, Welch's $t$ test). G, Normalized $\gamma$ amplitude per $20^{\circ}$ phase bin of the $\theta$ cycle for V1 during REM sleep. No significant differences were present between WT and DS mice. $\boldsymbol{H}$, High $\gamma$ amplitude peaked significantly later in the $\theta$ cycle than low $\gamma$ in both genotypes $(* p<0.005$, Wilcoxon test).

WT mice showed that $\theta$ phase modulated the amplitude of low and high $\gamma($ Fig. $1 E)$. Although this pattern was also present in DS mice, the modulation of $\gamma$ power by $\theta$ phase was significantly impaired for both frequency ranges (Fig. $1 F$ ). The $\theta$ phase at which $\gamma$ amplitude peaked was similar between genotypes, with high $\gamma$ peaking significantly later in the $\theta$ cycle than low $\gamma$ for both WT and DS mice (Fig. 1G,H). Average REM sleep duration was similar between WT and DS mice (48.9 \pm 4.2 and $46.6 \pm 3.0 \mathrm{~s}$, respectively; $t_{(26)}=0.45, p=0.66, t$ test), thereby excluding decreased REM sleep duration as a potential cause for impaired $\theta-\gamma$ coupling strength (Bandarabadi et al., 2019). Similar results were obtained from epochs during active wakefulness (Fig. 2), although in both WT and DS mice, modulation of high $\gamma$ oscillations was largely absent, and modulation of both low and high $\gamma$ frequencies was lower when compared with REM sleep (Fig. 2F-I). These data indicate that cortical $\theta-\gamma$ coupling is attenuated in juvenile DS mice, which cannot be explained by changes in $\theta$ or $\gamma$ power. 




$\mathbf{E}$



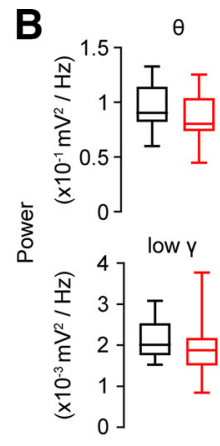

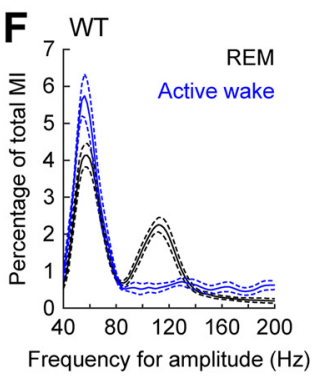

G
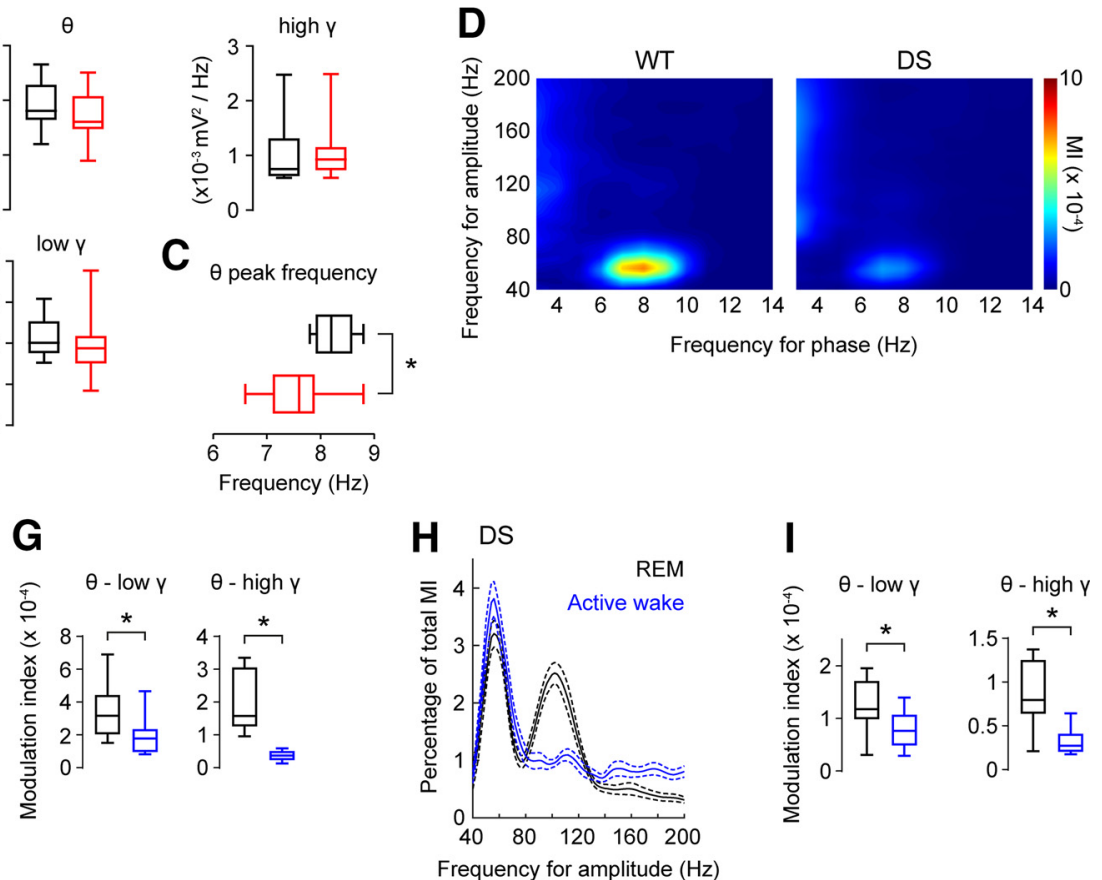

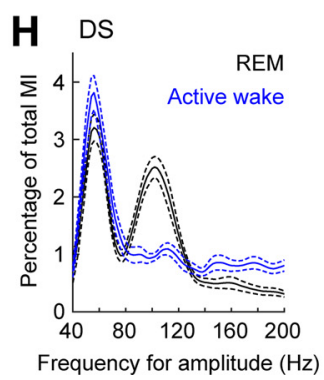

I

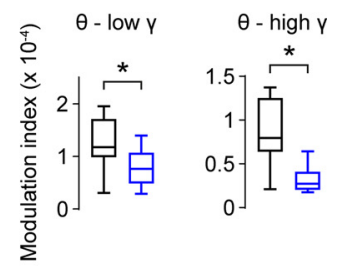

Figure 2. Deficient cortical $\theta-\gamma$ coupling during active wakefulness in DS mice. A, Average V1 LFP power spectra during wakefulness in WT (black) and DS (red) mice. No significant differences were present between genotypes in power within $\theta(5-10 \mathrm{~Hz})$, low $\gamma(40-90 \mathrm{~Hz})$, or high $\gamma(90-160 \mathrm{~Hz})$ frequency ranges $(\boldsymbol{B})$. $\boldsymbol{C}$, Peak $\theta$ frequency was significantly reduced in DS mice $\left(t_{(22.7)}=3.5, * p=0.002\right.$, Welch's $t$ test). $\boldsymbol{D}$, Average phase-amplitude comodulograms of V1 LFP during active wakefulness in WT ( $\left.n=9\right)$ and DS ( $\left.n=19\right)$ mice at P23. $\boldsymbol{E}, \theta$-Low $\gamma$ coupling was significantly reduced in DS mice $\left(t_{(7.9)}=2.7, * p=0.030\right.$, Welch's $t$ test). For both WT $(\boldsymbol{F}, \boldsymbol{G})$ and DS $(\boldsymbol{H}, \boldsymbol{I})$ mice, $\theta$ modulation of $\gamma$ amplitude was largely limited to low $\gamma$ frequencies during active wakefulness, while modulation of both low and high $\gamma$ frequencies was lower when compared with REM sleep.

\section{Impaired $\theta-\gamma$ coupling in the hippocampus of juvenile DS mice}

Previous studies indicate that $\theta$ oscillations recorded in the neocortex are volume-conducted currents originating from the hippocampus (Gerbrandt et al., 1978; Sirota et al., 2008). The hippocampus, a brain region that importantly contributes to the epileptic phenotype of DS mice (Liauard et al., 2013; Stein et al., 2019; Jansen et al., 2020), also displays $\theta-\gamma$ phase-amplitude coupling (Bragin et al., 1995; Buzsáki et al., 2003). To establish whether hippocampal $\theta-\gamma$ coupling is disturbed in DS mice, we assessed hippocampal LFP in WT $(n=6)$ and DS $(n=7)$ mice during REM sleep at P23. Similar to results obtained from V1, $\theta$ and $\gamma$ power were not significantly different between genotypes (Fig. $3 A, B$ ), whereas $\theta$ peak frequency was reduced in DS mice (Fig. $3 A$, inset). Variability in $\gamma$ power and $\theta-\gamma$ coupling appeared increased when compared with cortical LFP, which may be explained by slight variations in electrode position within the hippocampus since patterns of $\theta-\gamma$ coupling are different among hippocampal sublayers (Schomburg et al., 2014). Hippocampal $\theta-\gamma$ coupling was, however, robustly decreased in DS mice (Fig. 3C,D).

\section{Cortical $\theta-\gamma$ coupling normalizes in DS mice without spontaneous seizures}

The profound cortical $\theta-\gamma$ coupling (for both low and high $\gamma$ ) observed during REM sleep led us to limit subsequent analyses to this vigilance state. First, we assessed whether developmental changes in cortical $\theta$ - $\gamma$ coupling occurred over the three-week recording period by analyzing V1 LFP during REM sleep at 2, 7, 14 , and $21 \mathrm{~d}$ after surgery (i.e., P23, P28, P35, and P42; Fig. 4). $\theta-\gamma$ Coupling increased over this period in both WT and DS mice (Fig. $4 A, B$ ). Similar to the observations at P23, DS mice showed decreased $\theta-\gamma$ coupling when compared with WT mice
C

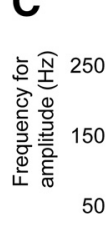

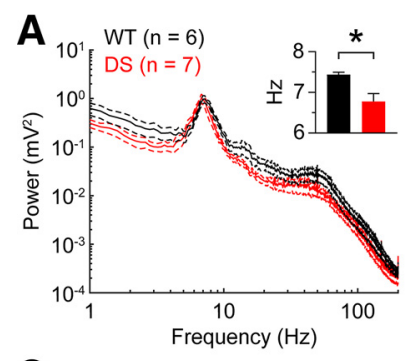

B
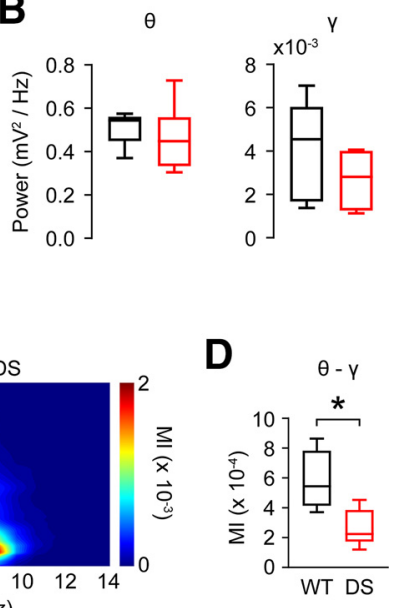

Figure 3. Deficient $\theta$ - $\gamma$ coupling in the hippocampus of DS mice. $\boldsymbol{A}$, Power spectral density of LFP recorded in the dorsal hippocampus during REM sleep in WT (black) and DS (red) mice. Peak $\theta$ frequency was significantly reduced in DS mice (inset; $t_{(6.9)}=3.2, * p=0.011$, Welch's $t$ test). No significant differences were present between genotypes in power within $\theta(5-10 \mathrm{~Hz})$ and $\gamma(40-300 \mathrm{~Hz})$ frequency ranges $(\boldsymbol{B})$. C, Average phase-amplitude comodulograms of the same LFP signals. $\boldsymbol{D}, \theta-\gamma$ Coupling was significantly reduced in DS mice $\left(t_{(8.1)}=3.64, * p=0.006\right.$, Welch's $t$ test $)$.

at P42 [MI values of $5.2 \pm 0.7 \times 10^{-4}$ and $10.4 \pm 1.5 \times 10^{-4}$, respectively; calculated for the total $\gamma$ range $(40-160 \mathrm{~Hz}) ; t_{(11)}=$ 3.2, $p=0.009$, Welch's $t$ test].

The recording period included postnatal week 4, during which spontaneous seizures are most prevalent in DS mice (Kalume et al., 2013). Accordingly, here, spontaneous seizures in DS mice were most often detected between P21-P28 (Fig. 4C). Three DS mice had a fatal seizure (during P24-P26), whereas a 


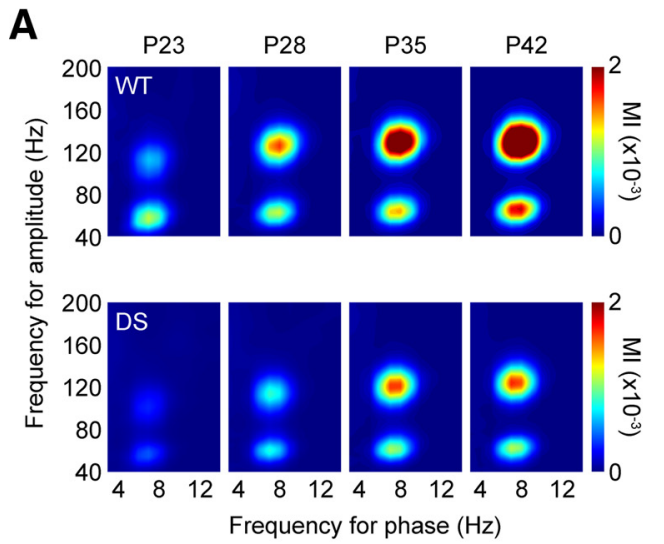

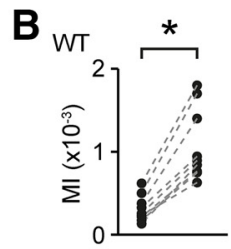

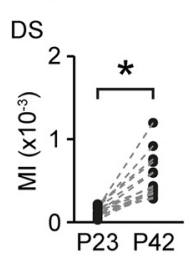

C

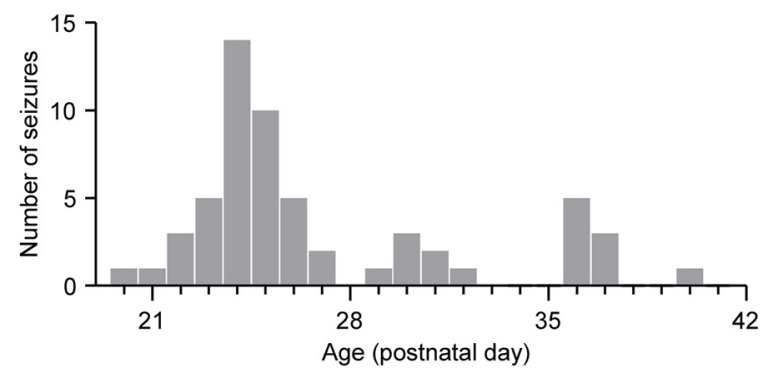

D



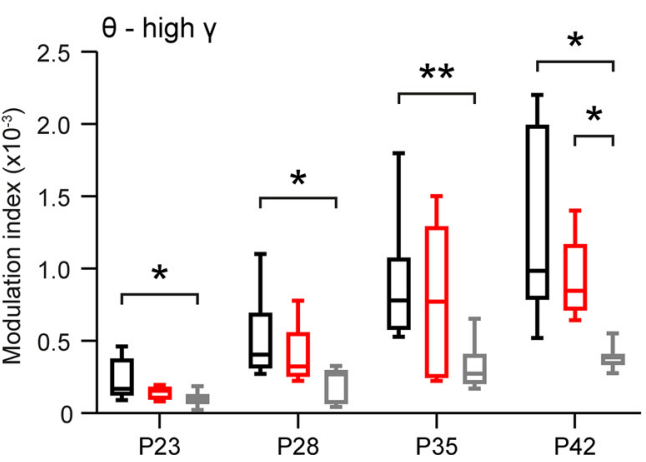

Figure 4. Persistently reduced cortical $\theta-\gamma$ coupling in DS mice that show spontaneous seizures. $\boldsymbol{A}$, Average phase-amplitude comodulograms of V1 showing progression of cortical $\theta$ - $\gamma$ coupling during postnatal weeks 4-7. B, Average Ml, calculated for $\theta(5-10 \mathrm{~Hz})$ and total $\gamma(40-160 \mathrm{~Hz})$, was markedly increased in both WT and DS mice at P42, when compared with P23 $\left(t_{(8)}=7.0\right.$ and $t_{(15)}=6.4$, respectively, $* p<0.0001$, paired $t$ test). C, Total frequency of spontaneous seizures in DS mice $(n=19)$. A subset of DS mice ( $\left.n=3\right)$ died during the recording period, between P24-P26. D, Progression of cortical $\theta-\gamma$ cross-frequency coupling for WT (black) and DS mice with (gray) and without (red) spontaneous seizures over the recording period. Note that at P23 the MI was significantly decreased compared with WT for both groups of DS mice, while at later ages this decrease was maintained only in DS mice with seizures for both low $(40-90 \mathrm{~Hz})$ and high $(90-160 \mathrm{~Hz}) \gamma\left(F_{(2,22)}=9.5, * p<0.05, * * p<0.005\right.$, repeated-measures ANOVA with Tukey's test).

subset of DS mice (seven out of 19) remained seizure-free over the three-week recording period. As early seizures, induced by hyperthermia or a chemoconvulsant, were shown to aggravate the epileptic phenotype and cognitive deficits in a knock-in DS mouse model (Salgueiro-Pereira et al., 2019), we assessed whether $\theta-\gamma$ coupling progressed differently in DS mice that did or did not express seizures during the recording period. Although seizure-free DS mice did show a decrease in cortical $\theta-\gamma$ coupling for both low and high $\gamma$ at baseline (P23), no significant differences were present at P28, P35, and P42 in these mice compared with WT littermates (Fig. 4D). In contrast, $\theta-\gamma$ coupling was persistently decreased, for both low and high $\gamma$, in DS mice that showed at least one seizure during the threeweek recording period (seizure count per mouse: $5.1 \pm 1.5$, range 1-19), when compared with WT mice (Fig. 4D).

\section{Decreased progression of cortical $\theta-\gamma$ coupling in DS mice is improved by CBD}

To test whether antiseizure drug treatment could improve attenuated cortical $\theta-\gamma$ coupling, a separate group of DS mice $(n=9)$ was used to assess the effects of CBD. CBD decreased seizure frequency in patients with DS (Devinsky et al., 2017), while in DS mice it decreased seizure frequency and severity and increased inhibitory neurotransmission in the hippocampus (Kaplan et al., 2017). Here, in DS mice, the progression of cortical $\theta$ - $\gamma$ coupling ceased after P35, contrasting the steady progression of $\theta-\gamma$ coupling observed in WT mice (Fig. 5A,B). DS mice received a single intraperitoneal injection of $\mathrm{CBD}$
$(100 \mathrm{mg} / \mathrm{kg})$ or vehicle at P35 using a randomized crossover design at an interval of 24 h. $\theta-\gamma$ Coupling was assessed in V1 LFP during REM sleep up to $5 \mathrm{~h}$ after intraperitoneal injection, during which plasma and brain CBD levels are high in mice (Deiana et al., 2012). When compared with vehicle, acute treatment of DS mice with CBD resulted in a modest but consistent increase in $\theta-\gamma$ coupling (Fig. $5 C, D$ ).

\section{Attenuation of cortical $\theta-\gamma$ coupling precedes seizures following hippocampal-specific knock-out of Scn1a}

The early attenuation of cortical $\theta$ - $\gamma$ coupling that was observed in DS mice at P23 occurred regardless of the epileptic phenotype. Thus, the deficit in cross-frequency coupling may be directly related to the inhibitory dysfunction caused by impaired sodium currents in the DS model (Yu et al., 2006). Alternatively, attenuated coupling may result from a secondary effect of inhibitory dysfunction on cortical connectivity during critical period plasticity (Takesian and Hensch, 2013; Cardin, 2018). We aimed to address this issue by introducing the Scn1a defect at adult age, using local brain injections of an AAV vector expressing mCherry-Cre in P42-P56 mice in which exon 8 of the Scnla gene is floxed by LoxP sites (in one or both copies of the gene, i.e., $S c n 1 a^{\mathrm{fl} /+}$ or $S c n 1 a^{\mathrm{fl} / \mathrm{fl}}$, respectively). This approach additionally allowed assessment of the effects of brain region-specific $\mathrm{Na}_{\mathrm{V}} 1.1$ dysfunction on $\theta-\gamma$ coupling.

Hippocampal ablation of $\mathrm{Na}_{\mathrm{V}} 1.1$ results in an increased susceptibility to seizures (Stein et al., 2019; Jansen et al., 2020). Here, we studied the effect of exposure to Cre recombinase in the 
dorsal and ventral hippocampus (Fig. 6A) of $S c n 1 a^{\mathrm{fl} / \mathrm{fl}}$ mice, resulting in complete $\mathrm{Na}_{\mathrm{V}} 1.1$ ablation, and $S c n 1 a^{\mathrm{fl} /+}$ mice, to study also partial $\mathrm{Na}_{\mathrm{V}} 1.1$ ablation (Fig. $6 B$ ) which may be more relevant in light of the haploinsufficiency observed in patients and Scn1a $a^{-1+}$ DS mice. Within $28 \mathrm{~d}$ after injection, all $\operatorname{Scn} 1 a^{\mathrm{fl} / \mathrm{fl}}$ mice and the majority of $S c n 1 a^{\mathrm{fl} /+}$ mice developed IISs ( $n=6 / 6$ and $n=6 / 7$, respectively; Fig. $6 D$ ) and spontaneous seizures $(n=6 / 6$ and $n=5 / 7$, respectively; Fig. $6 C, E$ ), whereas neither were observed in WT controls injected with AAVmCherry-Cre $(n=7)$. Statistical comparison indicated a significant increase in seizure count for $S c n 1 a^{\mathrm{fl} / \mathrm{fl}}$ and $S c n 1 a^{\mathrm{fl} /+}$ mice when compared with controls $(18.8 \pm 6.8$ and $9.4 \pm 3.8$ seizures, respectively; $H_{(2)}=11.7$, $p<0.05$, Kruskal-Wallis with Dunn's test), but seizure count did not differ significantly between the two genotypes $(p=0.68)$. Average onset of IIS was $11.5 \mathrm{~d}$ (range 9-14), while the first seizure was observed $13.1 \mathrm{~d}$ (range 10-18) after injection. Cortical $\theta$-low $\gamma$ coupling was impaired already on day 7 after injection for $\operatorname{Scn} 1 a^{\mathrm{fl} / \mathrm{fl}}$ mice (Fig. $6 F, G$ ). Also, $\theta$-high $\gamma$ coupling was impaired at this time in $S_{c n} 1 a^{\mathrm{fl} / \mathrm{fl}}$ and $S_{c n} 1 a^{\mathrm{fl} /+}$ mice (Fig. $6 F$, $H$ ). Modulation of both $\gamma$ frequency ranges did not recover over subsequent weeks (Fig. $6 G, H)$. Power changes were limited to an increase in $\gamma$ power in $S c n 1 a^{\mathrm{fl} / \mathrm{fl}}$ mice on day 21 after injection $\left(1.5 \pm 0.1 \times 10^{-3}\right.$ and $2.2 \pm 0.3 \times 10^{-3} \mathrm{mV}^{2} / \mathrm{Hz}$, on days 2 and 21 , respectively; $t_{(6)}=3.1, p=0.042$, paired $t$ test). These data indicate that attenuation of cortical $\theta-\gamma$ coupling precedes IIS and spontaneous seizures following hippocampal deletion of $\mathrm{Na}_{\mathrm{V}} 1.1$, independent of changes in power spectral density.

\section{Attenuation of $\theta$-high $\gamma$ coupling occurs independently of seizures following cortical-specific knock-out of Scn1a} In DS mice, both hippocampal and cortical regions may contribute to seizures (Jansen et al., 2020), and inhibitory dysfunction has been demonstrated in both structures (Yu et al., 2006; Tai et al., 2014). We therefore studied the effect of local cortical knockout of Scnla by injecting AAV-mCherry-Cre in V1 in Scn1 $a^{\mathrm{fl} /+}$ and $S c n 1 a^{\mathrm{fl} / \mathrm{fl}}$ mice, and WT controls (Fig. $7 A, B$ ). Interestingly, all $\operatorname{Scn} 1 a^{\mathrm{f} / \mathrm{fl}}$ mice developed IIS during the recording period, whereas this was the case for only a subset of $\operatorname{Scn} 1 a^{\mathrm{f} / /+}$ mice ( $n=6 / 6$ and $n=2 / 7$, respectively; Fig. $7 D)$. Spontaneous seizures were observed in a subset of $\operatorname{Scn} 1 a^{\mathrm{f} / \mathrm{f}}$ mice $(n=2 / 6)$, but never in $S c n 1 a^{\mathrm{f} / /+}$ mice (Fig. 7E). Previously, we reported a higher incidence of seizures in $\operatorname{Scn} 1 a^{\mathrm{fl} / \mathrm{fl}}$ mice $(n=6 / 6)$ following cortical injections with an AAV vector expressing GFP-Cre under the CMV promotor (Jansen et al., 2020). As the discrepancy with our current data suggests a greater potency of the latter AAV vector, we tested whether this vector (AAV-GFP-Cre) would result in seizures following cortical injections in $6 \mathrm{Scn} 1 a^{\mathrm{fl} /+}$ mice. Again, none of the $\operatorname{Scn} 1 a^{\mathrm{fl} /+}$ mice developed seizures, indicating that homozygous, but not heterozygous, knock-out of Scnla in V1 predisposes animals to develop spontaneous seizures. Early attenuation of $\theta-\gamma$ coupling, evident $7 \mathrm{~d}$ after injection, was restricted to
B

DS



D

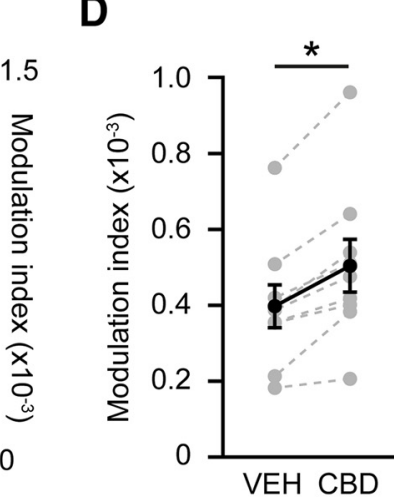

Frequency for phase $(\mathrm{Hz})$

CBD

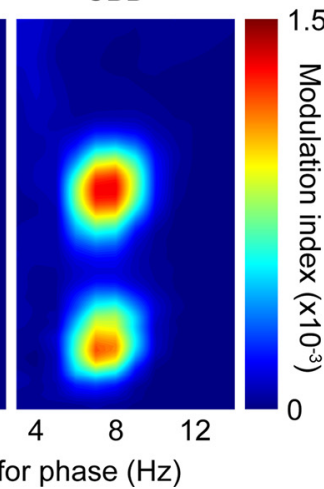

Figure 5. Acute treatment with CBD improves progression of $\theta-\gamma$ coupling in DS mice. WT mice showed steady progression of average $\theta$ - $\gamma$ cross-frequency coupling over time [A; calculated for total $\left.\gamma(40-160 \mathrm{~Hz}) ; F_{(3,8)}=15.5\right]$, Figure 2, excluding DS mice that died during the recording $(n=3)$. C Average phase-amplitude comodulograms of V1 $\theta(5-10 \mathrm{~Hz})$ and total $\gamma(40-160 \mathrm{~Hz})$, was significantly increased following treatment with $\mathrm{CBD}\left(t_{(8)}=5.1\right.$, $* p=0.0009$, ratio paired $t$ test).

the high $\gamma$ frequency range and persisted in $\operatorname{Scn} 1 a^{\mathrm{fl} / \mathrm{fl}}$ mice but recovered in $\operatorname{Scn} 1 a^{\mathrm{fl} /+}$ mice (Fig. $\left.7 F-H\right)$. Power changes were limited to an increase in $\gamma$ power in $\operatorname{Scn} 1 a^{\mathrm{fl} /+}$ mice on day $21 \mathrm{after}$ injection $\left(1.8 \pm 0.2 \times 10^{-3}\right.$ and $2.4 \pm 0.2 \times 10^{-3} \mathrm{mV}^{2} / \mathrm{Hz}$, on days 2 and 21 , respectively; $t_{(6)}=12.1, p<0.0001$, paired $t$ test), while $\theta$ peak frequency was decreased in both $S_{c n} 1 a^{\mathrm{f} /}+$ and $\operatorname{Scn} 1 a^{\mathrm{fl} / \mathrm{fl}}$ on day 21 (difference of $-0.2 \pm 0.1$ and $-0.4 \pm 0.1 \mathrm{~Hz}$, respectively; $t_{(6)}=2.6, p=0.038$, and $t_{(5)}=3.9, p=0.012$, paired $t$ test). These observations suggest that cortical $\mathrm{Na}_{\mathrm{V}} 1.1$ is required for modulation of high $\gamma$ by $\theta$.

Hippocampal fast ripples and attenuated $\theta-\gamma$ coupling precede epilepsy onset following hippocampal-specific knock-out of Scn1a

In addition to cortical LFP, mice that were injected in the hippocampus had local LFP recorded from AAV injection sites. Hippocampal $\theta-\gamma$ coupling, $\theta$ and $\gamma$ power, and $\theta$ peak frequency decreased over time following injection in both $S c n 1 a^{\mathrm{fl} /+}$ and $\operatorname{Scn} 1 a^{\mathrm{fl} / \mathrm{fl}}$ mice (Fig. 8) and comodulograms showed modulation of different $\gamma$ frequency ranges, including those above $150 \mathrm{~Hz}$ (Fig. 9A). Interestingly, the $\gamma$ frequency range that showed the strongest modulation by $\theta$ phase decreased over time following local Scn1a knock-out (Figs. 8A, 9A). As such, the decrease in $\theta-\gamma$ coupling (Fig. $8 B$ ) was caused by 


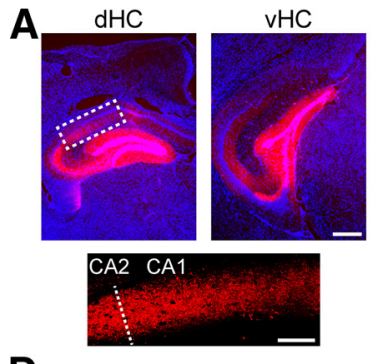

D

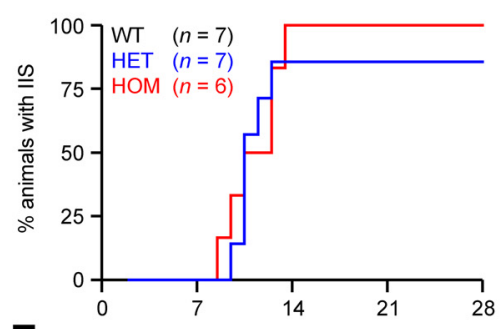

E

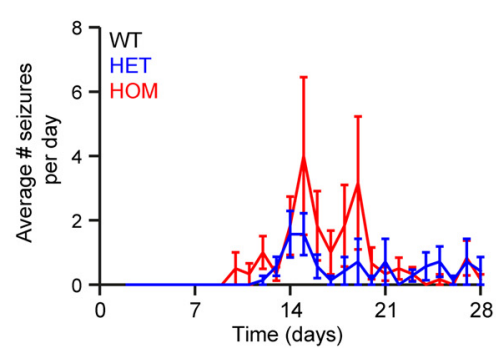

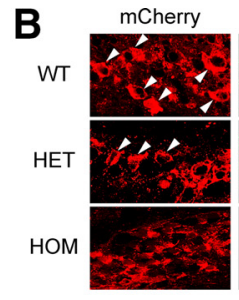


F
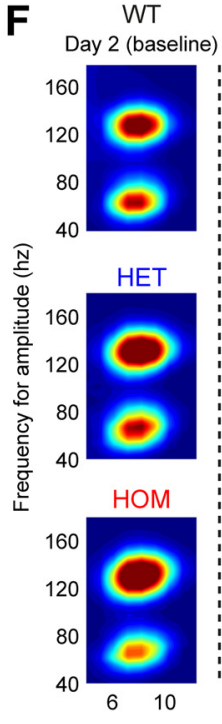
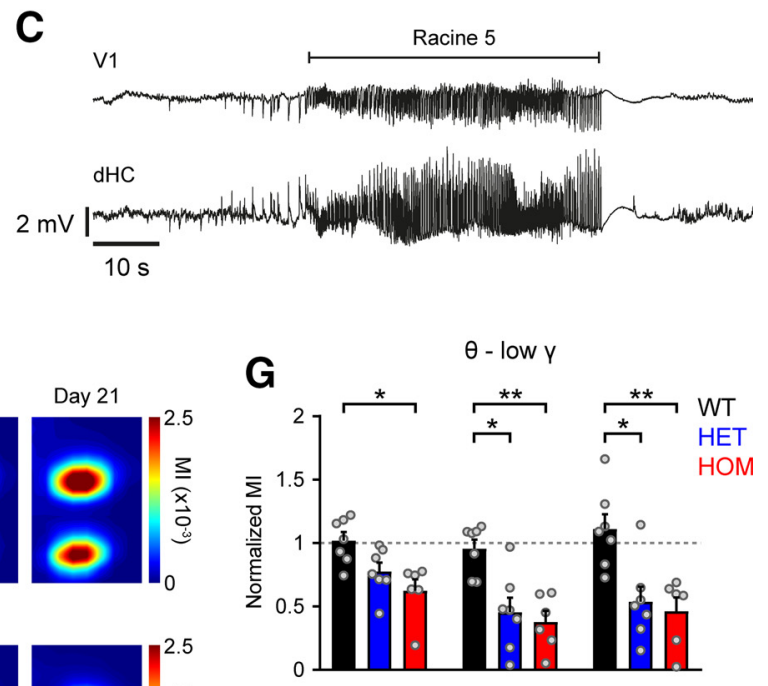

H
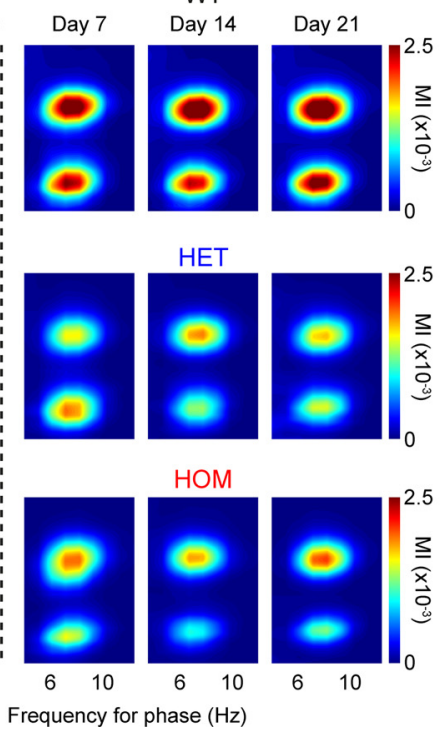

Figure 6. Chronic seizure activity following hippocampal ablation of Nav1.1 is preceded by decreases in cortical $\theta$ - $\gamma$ coupling. $\boldsymbol{A}$, Example of dorsal and ventral hippocampal areas (dHC and $\mathrm{VHC}$, respectively) infected by AAV-mCherry-Cre (red; Hoechst in blue). Scale bar: $500 \mu \mathrm{m}$. The targeted area included the CA1 and CA2 region (boxed area expanded in bottom inset; dashed line indicates border CA1/2; scale bar: $200 \mu \mathrm{m}$ ). B, Detail of hippocampal CA1/2 region showing reduced Nav1.1 staining in cells infected by AAV-mCherry-Cre (arrowheads indicate double-labeled cells) in $S_{n} 1 a^{\mathrm{fl} /+}$ (HET) and Scn $1 a^{\mathrm{fl} / \mathrm{fl}}$ (HOM) when compared with WT. Scale bar: $50 \mu \mathrm{m}$. C, Spontaneous seizure in a HOM mouse on day 19 after hippocampal AAV-mCherry-Cre. D, Proportion of HET $(n=7)$ and HOM $(n=6)$ mice with IISs, after hippocampal AAV-mCherry-Cre on day 0. No IIS were observed in WT ( $n=7)$. $\boldsymbol{E}$, Average frequency of spontaneous seizures following AAV-mCherry-Cre. $\boldsymbol{F}$, Average phase-amplitude comodulograms of V1 at different time points after injection. $\boldsymbol{G}, \boldsymbol{H}, \mathbf{M l}$, normalized to values obtained on day 2, was significantly decreased for both low $\gamma(40-90 \mathrm{~Hz} ; \boldsymbol{G})$ and high $\gamma(90-160 \mathrm{~Hz} ; \boldsymbol{H})$ frequencies in HET and HOM mice, when compared with WT mice $\left(F_{(2,17)}=14.5\right.$ and $F_{(2,17)}=24.9$, respectively, $* p<0.05$, **p $<0.005$; tw0-way ANOVA with Tukey's test).

a strong reduction in $\theta$-modulated high $\gamma$, while low $\gamma$ was not significantly affected (Fig. $8 C, D$ ).

Hippocampal fast ripples $(250-500 \mathrm{~Hz})$ appear to occur specifically in the seizure onset zone (Jefferys et al., 2012), independent of cell loss associated with hippocampal sclerosis (Jiruska et al., 2010). To study the association between fast ripples and local $\theta$ - $\gamma$ coupling following hippocampal-specific knock-out of $\operatorname{Scn} 1 a$, we inspected hippocampal LFP recordings for fast ripples over $12 \mathrm{~h}$ preceding the first spontaneous seizure. In 7 out of 13 animals $\left(n=3 S c n 1 a^{\mathrm{fl} /+}\right.$ and $n=4 S c n 1 a^{\mathrm{fl} / \mathrm{fl}}$ mice), we found fast ripples that were superimposed on interictal discharges (Fig. $9 B$ ) in either the ventral $(n=4)$ or dorsal $(n=3)$ hippocampus. Following exclusion of one animal with bilateral fast ripples, comparison of hippocampal $\theta-\gamma$ coupling ipsilateral and contralateral to the fast ripples revealed a profound reduction in average MI for the ipsilateral electrode (Fig. 9C). The difference between baseline and preictal MI was also significantly greater for the ipsilateral compared with the contralateral electrode $\left(-7.8 \pm 1.5 \times 10^{-4}\right.$ and $-2.1 \pm 0.6 \times 10^{-4}$, respectively; $p=0.002$, Mann-Whitney test). Similarly, the $\gamma$ frequency that showed the strongest modulation by $\theta$ phase was decreased in the hours preceding seizure activity, specifically for the ipsilateral electrode (Fig. 9D). The drop in $\gamma$ frequency between baseline and the preictal period was not significantly different between sides $(-79 \pm 19 \mathrm{~Hz}$ and $-36 \pm$
$18 \mathrm{~Hz}$ for ipsilateral and contralateral, respectively; $p=0.14$, Mann-Whitney test). These data confirm $\theta-\gamma$ coupling as a marker for epileptogenesis in these mice, as its attenuation precedes the first spontaneous seizure in an area corresponding to the seizure onset zone.

Impairment of voltage-gated sodium currents in inhibitory neurons attenuates $\theta-\gamma$ coupling and $\theta$ frequency in a computational model

Our in vivo experiments indicate that $\theta-\gamma$ coupling decreases before the first spontaneous seizure, suggesting that epilepsyrelated remodeling is not responsible for this deficit in network functioning. To test whether decreased $\theta-\gamma$ coupling may result from loss of voltage-gated sodium currents in inhibitory neurons, we developed a hippocampal network model in which we varied the amount of voltage-gated sodium channel $\left(\mathrm{Na}_{V}\right)$ function by decreasing their sodium conductance in modified Hodgkin-Huxley neurons representing fast-spiking BC neurons (Wang and Buzsáki, 1996) and OLM neurons (Tort et al., 2007). Synaptic connections between BC, OLM, and EX neurons were all-to-all (Fig. 10A) and five neurons of each type were included in the model. LFP generated by the model was dominated by $\theta$ oscillations both at baseline (BC: $10 \mathrm{mS} / \mathrm{cm}^{2}$, OLM: $35 \mathrm{mS} / \mathrm{cm}^{2}$ ) and after decreasing sodium conductance in inhibitory neurons (BC: $6 \mathrm{mS} / \mathrm{cm}^{2}$, OLM: $28 \mathrm{mS} / \mathrm{cm}^{2}$; Fig. 10B). $\theta$ Peak frequency 
A

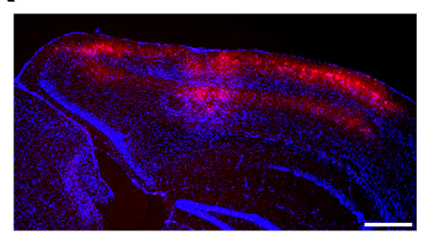

D

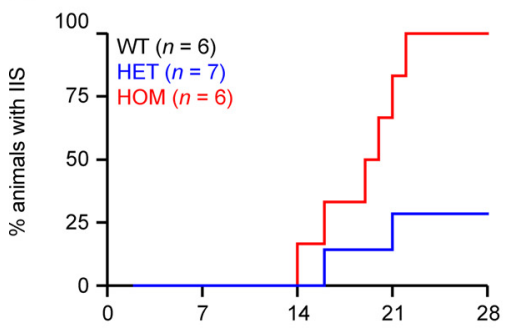

$\mathbf{E}$

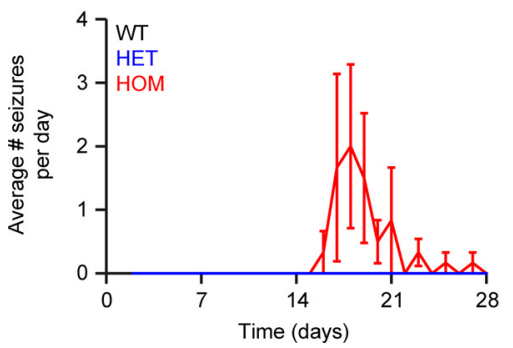

B

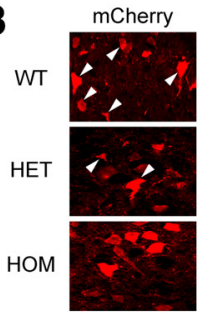

$\mathbf{F}$

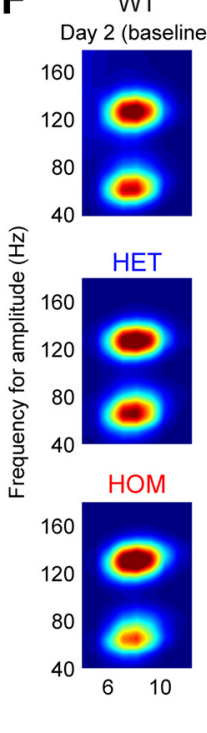

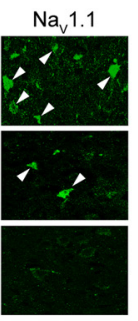
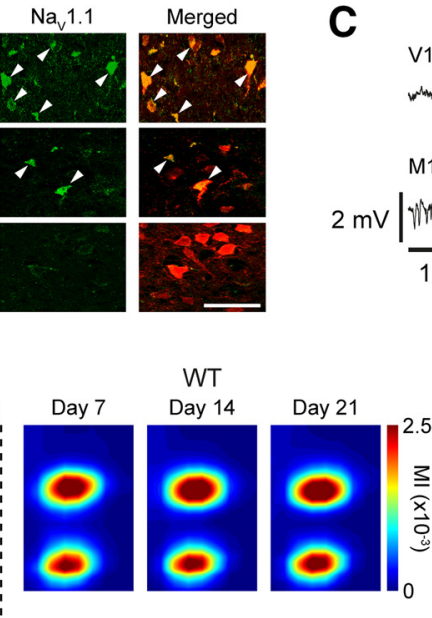

G

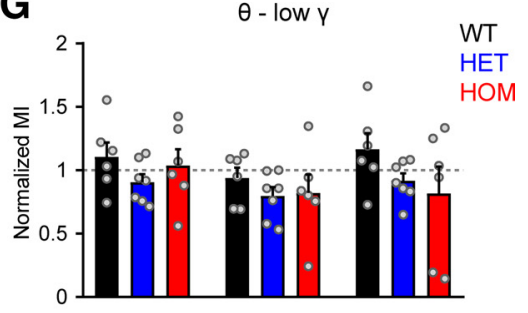

H



HOM
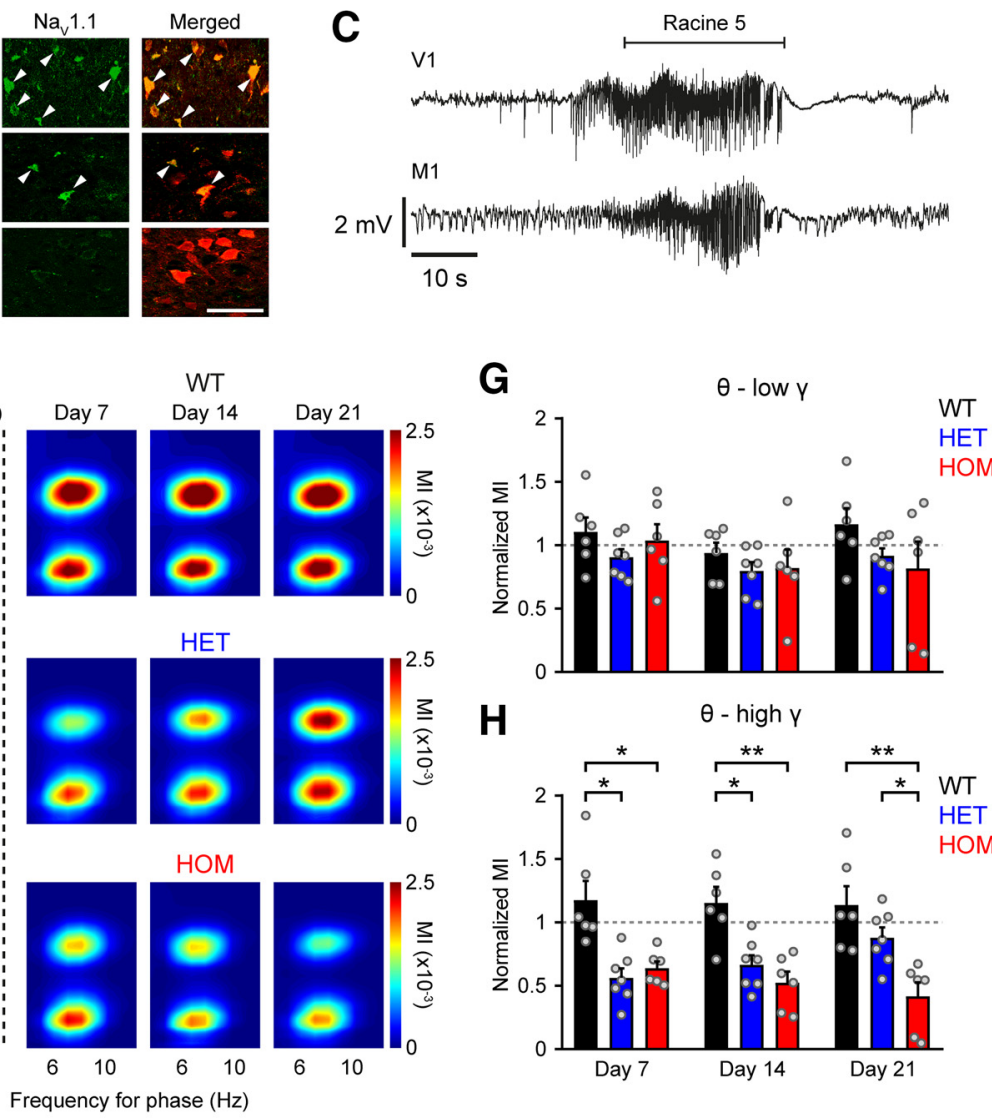

Figure 7. Cortical ablation of Nay 1.1 specifically decreases $\theta$-high $\gamma$ coupling. $\boldsymbol{A}$, Example of the V1 area infected by AAV-mCherry-Cre (red; Hoechst in blue). Scale bar: $500 \mu$ m.

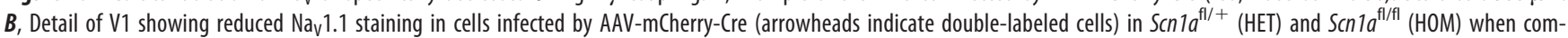
pared with WT. Scale bar: $50 \mu \mathrm{m}$. C, Spontaneous seizure recorded in an Scn $1 a^{\mathrm{fl} / \mathrm{fl}}$ mouse on day 18 after cortical AAV-mCherry-Cre. $\boldsymbol{D}$, Proportion of HET ( $n=7$ ) and H0M ( $n=6$ ) mice with IISs, following cortical AAV-mCherry-Cre on day 0. No IIS were observed in WT mice $(n=6)$. $\boldsymbol{E}$, Average frequency of spontaneous seizures following injection of AAVmCherry-Cre. $\boldsymbol{F}$, Average phase-amplitude comodulograms of $\mathrm{V} 1$ at different time points after injection. $\boldsymbol{G}, \boldsymbol{H}$, MI, normalized to values obtained on day 2, was significantly decreased for high $\gamma(\boldsymbol{H})$, but not low $\gamma$, in HET and HOM mice when compared with WT mice $\left(F_{(2,16)}=18.5\right.$ and $F_{(2,16)}=1.3$, respectively, $* p<0.05$, $* * p<0.005$; tw0-way ANOVA with Tukey's test).

however was shifted to the left in case of impaired $\mathrm{Na}_{V}$ function when compared with baseline, while power in the $\gamma$ range was comparable $\left(9.49 \times 10^{-5}\right.$ and $9.51 \times 10^{-5}$, respectively; Fig. $10 C)$. Modulation of $\gamma$ by $\theta$ was present in both conditions, but reduced in case of impaired $\mathrm{Na}_{\mathrm{V}}$ function, which was most evident for $\gamma$ oscillations $>100 \mathrm{~Hz}$ (Fig. 10D). Impairment of inhibitory $\mathrm{Na}_{\mathrm{V}}$ function in this computational model thus faithfully replicates both the reduced $\theta$ frequency and reduced $\theta-\gamma$ coupling observed in DS mice.

To delineate the specific roles of the two populations of inhibitory interneurons in this model, we next systematically decreased $\mathrm{Na}_{V}$ function in either BC or OLM neurons. We found that the leftward shift in $\theta$ power results from $\mathrm{Na}_{\mathrm{V}}$ dysfunction in the OLM population (Fig. 10E). Decreasing $\mathrm{Na}_{\mathrm{V}}$ function in BC or OLM neurons had opposite effects on $\theta-\gamma$ coupling: decreasing $\mathrm{Na}_{\mathrm{V}}$ function in $\mathrm{BC}$ neurons alone impaired $\theta-\gamma \mathrm{MI}$, while decreasing $\mathrm{Na}_{\mathrm{V}}$ function in OLM neurons increased MI (Fig. 10F). Simultaneous reduction of $\mathrm{Na}_{\mathrm{V}}$ function in both BC and OLM neurons resulted in a progressive decrease in $\theta-\gamma$ MI over the high $\gamma(100-200 \mathrm{~Hz})$ range, while a slight increase followed by a decrease occurred over the low $\gamma$ $(40-100 \mathrm{~Hz})$ range. Thus, $\theta$-modulated high $\gamma$ is more strongly affected than low $\gamma$ in this computational model, which reproduces the in vivo results obtained following local Scn1a knock-out.

\section{Discussion}

We here report in juvenile DS mice impaired $\theta-\gamma$ phase-amplitude coupling, that persisted in mice that developed spontaneous seizures but recovered to WT levels in mice that remained seizure-free. Impaired $\theta-\gamma$ coupling was improved following acute CBD treatment. Hippocampal or cortical-specific knock-out of Scn1 $a$ impaired cortical $\theta-\gamma$ coupling, which preceded spontaneous seizures. Attenuated modulation of high $\gamma$ by $\theta$ in the hippocampus, which colocalized with fast ripple activity preceding the start of chronic epileptic activity, was reproduced in a computational model in which $\mathrm{Na}_{\mathrm{V}}$ dysfunction was selectively introduced in inhibitory neurons. Together, our findings indicate that $\theta-\gamma$ coupling may serve as an early indicator of inhibitory dysfunction and epileptogenesis in DS.

Dysfunction of inhibitory interneurons has been demonstrated in DS mouse models (Tai et al., 2014; Rubinstein et al., 2015; De Stasi et al., 2016; Goff and Goldberg, 2019), and may depend on age window or brain region (Favero et al., 2018; Almog et al., 2019). Reports on how inhibitory dysfunction affects network dynamics in DS mice appear more ambiguous. For instance, decreased $\delta$ power during non-REM sleep was reported in DS mice (Kalume et al., 2015), but changes in sleep-related $\delta$ power were not present in another DS model (Papale et al., 2013). Also, interneurons were hypoexcitable, but LFP power was unchanged in DS mice during the 

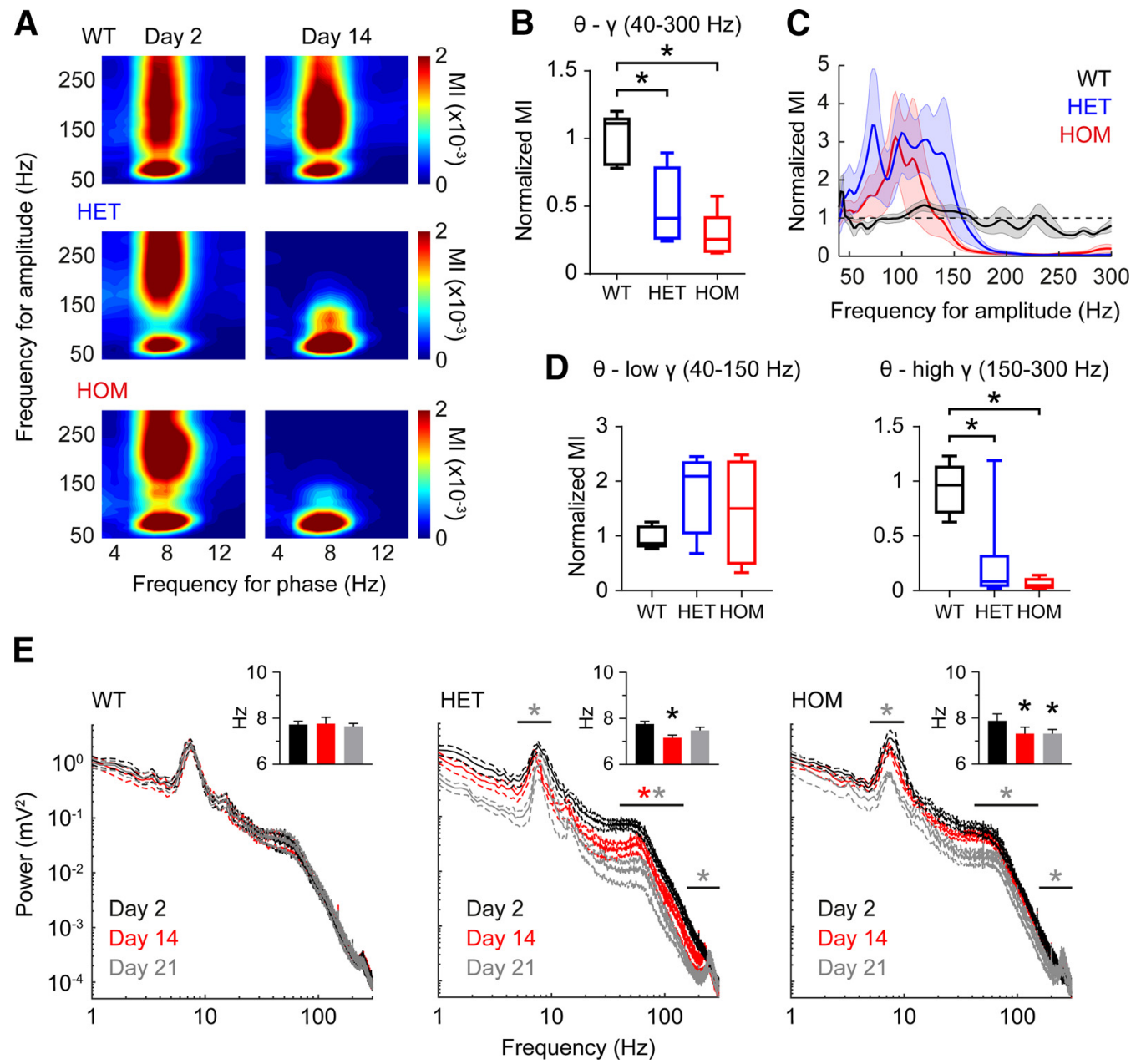

Figure 8. Deficient hippocampal $\theta-\gamma$ coupling and power following local ablation of Nav1.1. A, Average phase-amplitude comodulograms of LFP obtained from dorsal hippocampus during days 2 (left) and 14 (right) after hippocampal injection of mCherry-Cre. B, $\theta-\gamma$ Coupling was reduced in $\operatorname{Sen} 1 a^{\mathrm{f} / /+}$ and $\operatorname{Sen} 1 a^{\mathrm{f} / / \mathrm{l}}$ mice on day 14 (total $\theta-\gamma \mathrm{Ml}$ normalized to day 2; $F_{(2,17)}=$ $13.9, * p<0.01$, one-way ANOVA with Dunnett's test). C, MI normalized per 2-Hz $\gamma$ frequency bin revealed that Ml was specifically reduced for $\gamma$ frequencies $>150 \mathrm{~Hz}$, while showing large variation for the lower $\gamma$ range. $\boldsymbol{D}$, Statistical comparison revealed no difference for $\theta$-modulated low $\gamma\left(F_{(2,17)}=1.3, p=0.31\right)$, but a significant reduction for high $\gamma$ $\left(F_{(2,17)}=11.4, p=0.001\right)$ for both $\operatorname{Sen} 1 a^{\mathrm{fl} /+}$ and $\operatorname{Scn} 1 a^{\mathrm{fl} / \mathrm{fl}}$ mice $(* p=0.004$ and $* p=0.001$, ANOVA with Dunnett's test). E, Hippocampal LFP power spectral density during REM sleep in WT $(n=7), \operatorname{Scn} 1 a^{\mathrm{fl} /+}$ (HET, $\left.n=7\right)$, and $\operatorname{Scn} 1 a^{\mathrm{fl} / f \mathrm{l}}(\mathrm{HOM}, n=6)$ mice during days 2 (black), 14 (red), and 21 (gray) after hippocampal injection of mCherry-Cre. Power was significantly reduced only in HET and HOM mice. Asterisks of corresponding color indicate significant differences of power in $\theta(5-10 \mathrm{~Hz})$, low $\gamma(40-150 \mathrm{~Hz})$, or high $\gamma(150-300 \mathrm{~Hz})$ on day $2(* p<0.05$, paired $t$ tests).

preepileptic period (De Stasi et al., 2016). Clinically, patients with DS often have a normal background EEG at one to two years of age, while seizures already manifest at this time (Bureau and Dalla Bernardina, 2011; Wirrell et al., 2017). We did not detect differences in $\theta$ or $\gamma$ power during REM sleep and active wakefulness in DS versus WT mice. This contrasts with a previous study reporting decreased $\theta$ power during REM sleep in DS mice (Kalume et al., 2015), which may be explained by differences in mouse strain background and the cortical area studied. Also, we used a strict cutoff in $\theta / \delta$ ratio to delineate epochs of REM sleep and active wakefulness, which may have rendered our analyses less sensitive to subtle differences in $\theta$ power. Nevertheless, our results indicate that $\theta-\gamma$ coupling is a more sensitive measure of network dysfunction in DS than power spectral density.

Knock-out of Scn1a appears to specifically affect inhibitory populations, with reduced sodium currents lowering their excitability (Yu et al., 2006; Ogiwara et al., 2007; Tai et al., 2014; Favero et al., 2018), although increased sodium currents have been reported in hippocampal excitatory neurons (Mistry et al.,
2014). Such hyperexcitability of hippocampal excitatory neurons may be attributed to seizure-induced remodeling in DS mice (Dutton et al., 2017; Salgueiro-Pereira et al., 2019). Importantly, chronic epilepsy may impair $\theta$ - $\gamma$ coupling, as demonstrated for the hippocampal CA1 region in a rat model of temporal lobe epilepsy (Lopez-Pigozzi et al., 2016). Similarly, impairments in $\theta-\gamma$ coupling were recently found in the hippocampus of rats following local knock-down of $S c n 1 a$, whereas no epileptiform activity was observed (Sakkaki et al., 2020). Although such activity may not be detected since recordings were performed during wakefulness, when IIS are rare (Kalume et al., 2015), $\mathrm{Na}_{\mathrm{V}} 1.1$ dysfunction was induced only in CA1 of the dorsal hippocampus (Sakkaki et al., 2020), which may prove insufficient to cause epileptiform activity. In our study, the majority of the hippocampus was targeted, such that subregional effects of $\mathrm{Na}_{\mathrm{V}} 1.1$ dysfunction cannot be discerned. DS mice and mice with local hippocampal or cortical knock-out of Scnla showed early impairment of $\theta-\gamma$ coupling before, or in the absence of, chronic epileptic activity. This impairment was transient in seizure-free DS mice, but persisted in mice with spontaneous seizure activity. Thus, our data 
A
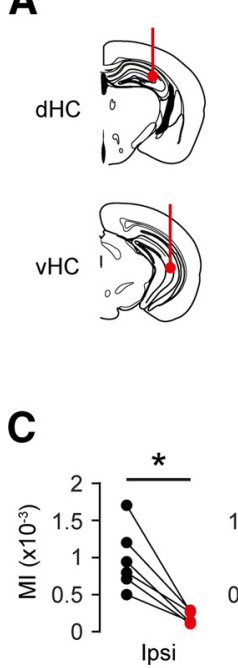
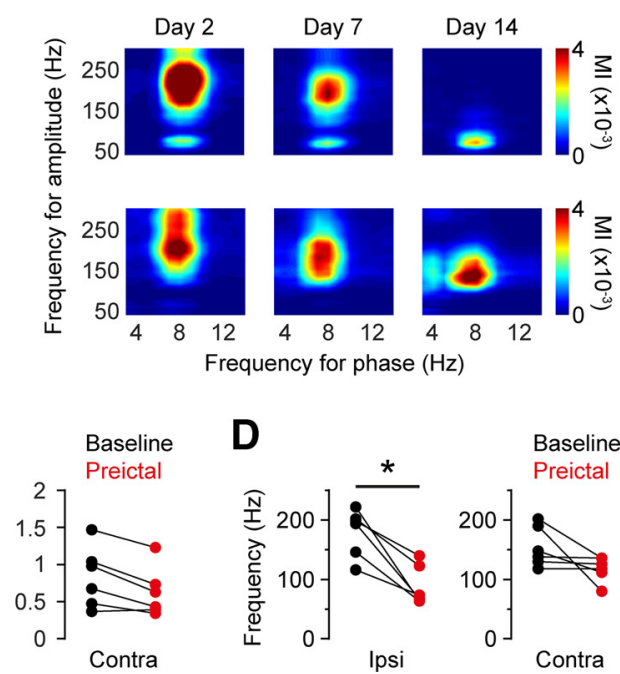

D

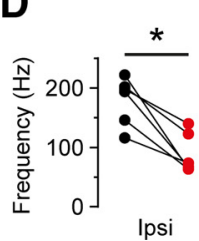

B

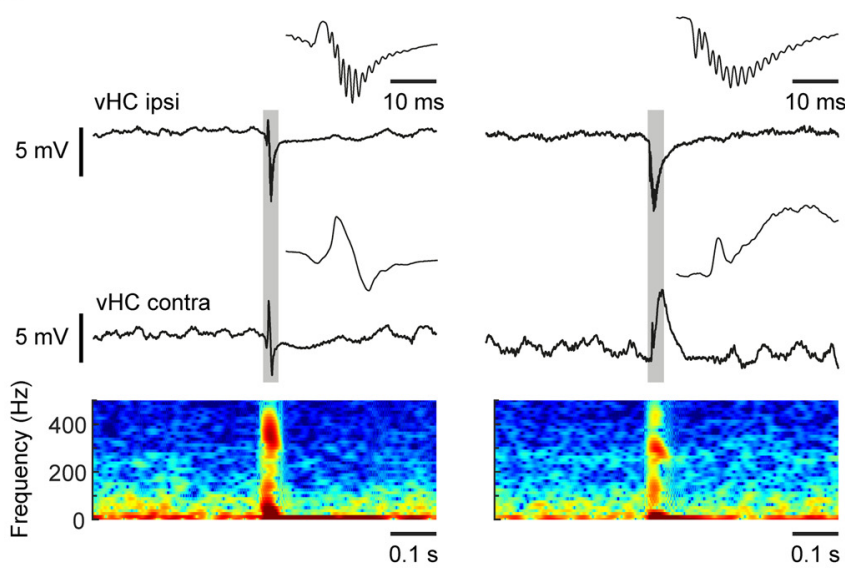

Figure 9. $\theta$ - $\gamma$ Coupling is affected more in areas that show fast ripples following hippocampal Nay 1.1 ablation. $\boldsymbol{A}$, Example phase-amplitude comodulograms of LFP in the dorsal and ventral hippocampus (dHC and vHC, respectively) following hippocampal injection of AAV-mCherry-Cre on day 0 in an Scn $1 a^{\mathrm{f} / \mathrm{fl}}$ mouse. B, Examples of fast ripples observed in the ventral hippocampus of an $\operatorname{Sen} 1 a^{\mathrm{fl} / \mathrm{fl}}$ (left) and $\mathrm{S} \mathrm{Cn} \mathrm{a}^{\mathrm{fl} /+}$ (right) mouse. Fast ripples (detailed in insets, corresponding to the shaded area) were observed unilaterally (vHC ipsi) and had a high power in the 250to $500-\mathrm{Hz}$ range, as shown by the spectrogram of the ipsilateral $\mathrm{vHC}$ signal at the bottom. Their onset preceded or coincided with IISs on the contralateral side (vHC contra). C, For hippocampal LFP that contained fast ripples (ipsi), $\theta-\gamma$ coupling, assessed by the Ml (averaged for the total $\gamma$ frequency range, $40-300 \mathrm{~Hz}$ ), was significantly decreased in the $12 \mathrm{~h}$ preceding the first seizure (preictal) when compared with day 2 after injection (baseline; $* p=0.031$, Wilcoxon test). In parallel, the $\gamma$ frequency showing peak MI was significantly reduced $(\boldsymbol{D} ; p=0.031$, Wilcoxon test). MI changes of contralateral LFP that did not contain fast ripples (contra) did not reach statistical significance.

A

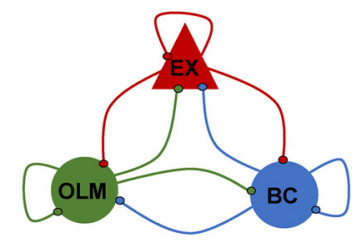

C

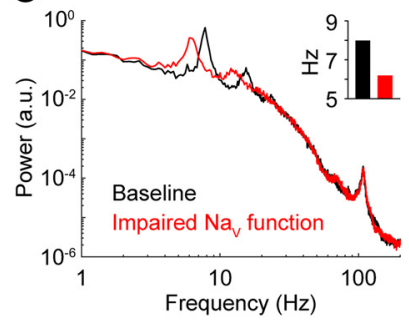

B

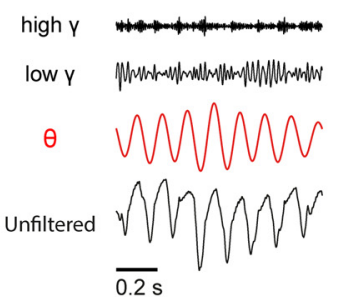

D

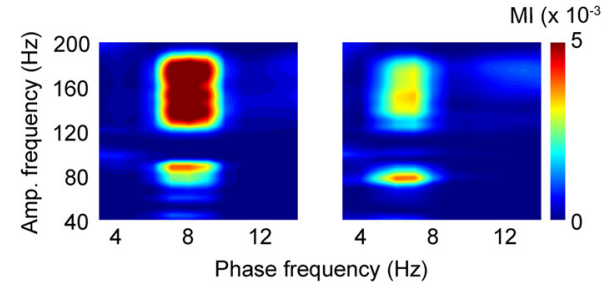

E

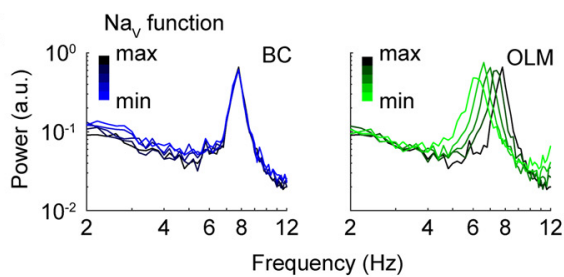

$\mathbf{F}$

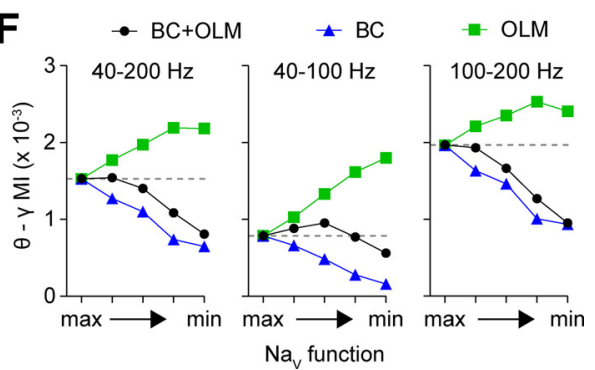

Figure 10. Modeling impaired $\mathrm{Na}_{\mathrm{y}}$ functioning in inhibitory neurons replicates the attenuated $\theta-\gamma$ coupling and decreased $\theta$ frequency observed after ablation of Nay 1.1. A, Schematic of the computational network consisting of five EX, OLM, and fast-spiking BC neurons each with all-to-all connectivity. Full details about the model are provided in Extended Data Figure 10-1. $\boldsymbol{B}$, Example traces of raw, $\theta$-filtered $(\theta ; 5-10 \mathrm{~Hz})$, low $\gamma$-filtered (low $\gamma ; 40-100 \mathrm{~Hz})$, and high $\gamma(100-200 \mathrm{~Hz})$ filtered LFP from the model with normal (baseline) and impaired Nav function in both OLM neurons ( 35 and $28 \mathrm{mS} / \mathrm{cm}^{2}$, respectively) and BC neurons (10 and $6 \mathrm{mS} / \mathrm{cm}^{2}$, respectively). C, Average LFP power spectra from the same simulations used in $\boldsymbol{B}$ with normal (black) or impaired (red) inhibitory $\mathrm{Na}_{\mathrm{v}}$ function, showing intact $\gamma$ power and a reduced $\theta$ peak frequency in the latter (C, inset). $\boldsymbol{D}$, Phase-amplitude comodulograms of these simulations show impaired $\theta$-modulated $\gamma$. E, Stepwise impairment of $\mathrm{Na}_{v}$ function specifically in $\mathrm{BC}$ neurons (blue, left plot) or OLM neurons (green, right plot) resulted in a leftward shift in peak $\theta$ frequency for OLM neurons (black: $35 \mathrm{mS} / \mathrm{cm}^{2}$, bright green: $28 \mathrm{mS} / \mathrm{cm}^{2}$, steps of $1.75 \mathrm{mS} / \mathrm{cm}^{2}$ ), but not for BC neurons (black: $10 \mathrm{mS} / \mathrm{cm}^{2}$, bright blue: $6 \mathrm{mS} / \mathrm{cm}^{2}$, steps of $1 \mathrm{mS} / \mathrm{cm}^{2}$ ). $\boldsymbol{F}$, Average $\theta-\gamma$ MI calculated for total $\gamma$ (left), low $\gamma$ (center), and high $\gamma$ (right) with decreasing levels of Nav function in BC neurons (blue), OLM neurons (green) and both BC and OLM neurons (black).

indicate that $\theta-\gamma$ coupling is impaired early in all DS mice, but persistence of impaired $\theta-\gamma$ coupling at later stages is dependent on seizure-induced network remodeling.

Over postnatal weeks $4-7$, WT and DS mice showed an increase in cortical $\theta-\gamma$ coupling. In mice, this is a developmental period of high cortical plasticity that starts with maturation of fast-spiking parvalbumin-positive interneurons (Takesian and Hensch, 2013; Cardin, 2018). In seizure-free DS mice, we found that $\theta$ - $\gamma$ coupling is impaired at P23, but normalized to WT levels at P28-P42. This evolution roughly corresponds to developmental data from cortical parvalbumin-positive interneurons that show decreased firing only at P18-P21, but not at P35-P56, suggesting that their dysfunction contributes to the onset, but not chronification, of epilepsy in DS (Favero et al., 2018). Here, local cortical heterozygous knock-out of Scn1a resulted in transient attenuation of $\theta-\gamma$ coupling, which may reflect such temporary inhibitory dysfunction. CBD, which increases inhibitory neurotransmission in DS mice (Kaplan et al., 2017), increased 
$\theta-\gamma$ coupling, supporting a link between inhibitory functioning and $\theta-\gamma$ coupling. Evidence that $\theta$ rhythms modulate a greater proportion of inhibitory interneurons when compared with excitatory neurons (Csicsvari et al., 1999; Sirota et al., 2008) suggests that inhibitory dysfunction particularly impacts $\theta-\gamma$ coupling. This is further attested by impaired modulation of hippocampal $\gamma$ amplitude by $\theta$ phase in mice that lacked inhibition onto parvalbumin-positive interneurons, while $\theta$ power and peak frequency was reduced (Wulff et al., 2009). Similarly, we found a reduced $\theta$ peak frequency in DS mice, and following local $\mathrm{Na}_{V} 1.1$ ablation. Decreased $\mathrm{Na}_{V} 1.1$ expression was also observed in a mouse model of Alzheimer's disease, as well as in patients, providing an explanation for dysfunction of parvalbumin-positive interneurons (Verret et al., 2012). Since impaired $\theta$ - $\gamma$ coupling has been demonstrated in Alzheimer's models (Ittner et al., 2014; Zhang et al., 2016), similar mechanisms may underlie such rhythmopathies in Alzheimer's disease and DS models.

In our computational model, decreases in $\theta$ peak frequency could be attributed to $\mathrm{Na}_{\mathrm{V}}$ dysfunction in OLM neurons. In animal models of temporal lobe epilepsy, hippocampal $\theta$ frequency is decreased (Dugladze et al., 2007; Kilias et al., 2018) and degeneration of OLM neurons, resulting in loss of dendritic inhibition, has been observed (Cossart et al., 2001). Thus, decreased $\theta$ frequency appears to be a general feature of the epileptic hippocampus, and dysfunction and/or loss of OLM neurons may underlie this phenomenon. Although (parvalbuminergic) BC neurons appear to maintain their function in the epileptic hippocampus (Cossart et al., 2001; Wittner et al., 2005), dysfunction of these neurons has been related to impaired $\theta-\gamma$ coupling (LopezPigozzi et al., 2016), which we confirmed here by modeling BC $\mathrm{Na}_{\mathrm{V}}$ dysfunction. Together, our findings suggest that decreased $\theta$ frequency and $\theta-\gamma$ coupling reflect the impaired inhibitory functioning observed in DS mice. Network dynamics underlying cross-frequency coupling, however, are complex, and different factors may affect $\theta-\gamma$ coupling in other disease models.

We distinguished low and high $\gamma$ bands, supported by evidence that mechanisms underlying these oscillations are different (Buzsáki and Wang, 2012). High $\gamma$ (above 80-90 Hz) peaks at a different phase of the $\theta$ cycle than low $\gamma$ (Belluscio et al., 2012), as confirmed by our data, and strongly correlates with neuronal spiking (Ray and Maunsell, 2011). Local $\mathrm{Na}_{\mathrm{V}} 1.1$ dysfunction impaired local $\theta$-modulated high, but not low, $\gamma$ oscillations, which was computationally replicated. This suggests that $\mathrm{Na}_{\mathrm{V}} 1.1$ dysfunction impairs modulation of local neuronal firing by $\theta$, as previously shown for CA1 neurons following local $\mathrm{Na}_{\mathrm{V}} 1.1$ knock-down (Sakkaki et al., 2020). The critical role for fast-spiking $\mathrm{BC}$ in regulating spike timing by somatic inhibition (Cardin, 2018) may explain these early deficits in $\theta$-high $\gamma$ coupling.

Increased hippocampal $\theta-\gamma$ coupling is associated with memory recall in rodents (Tort et al., 2009) and humans (Axmacher et al., 2010; Heusser et al., 2016). Memory impairment is frequently observed in patients with temporal lobe epilepsy (Helmstaedter and Elger, 2009; Vlooswijk et al., 2010). Although we did not relate changes in $\theta-\gamma$ coupling to learning, previous studies indicate that context-dependent and spatial memory are impaired in DS mouse models (Han et al., 2012; Salgueiro-Pereira et al., 2019). Cognitive deficits were only present in adult DS mice that had experienced seizures at juvenile age (Salgueiro-Pereira et al., 2019), which may be related to persistent deficits in $\theta-\gamma$ coupling that we only observed in adult DS mice with juvenile-onset seizures. The hippocampus appears to critically contribute to spatial memory deficits and the epileptic phenotype in DS mice (Liauard et al., 2013; Stein et al., 2019).
Our data suggest that impaired $\theta-\gamma$ coupling precedes seizures and associates unilaterally with fast ripple activity in the hippocampus, a marker for epileptogenesis (Jefferys et al., 2012). Further studies are required to translate these findings to other epilepsy models. Reductions in $\theta$ frequency in such models have been suggested to underlie cognitive deficits in epilepsy (Shuman et al., 2017; Kilias et al., 2018), but in our experiments occurred regardless of epileptic activity. Similarly, local knock-down of $\mathrm{Na}_{\mathrm{V}} 1.1$ in the medial septum, which provides input to the hippocampus, decreased $\theta$ frequency and disrupted spatial memory in rats (Bender et al., 2016) without inducing seizure activity (Bender et al., 2013), indicating that regions other than the hippocampus may contribute to impaired spatial memory and $\theta$ rhythmogenesis in DS. To recapitulate rhythmopathies in DS, the precision of computational models may therefore be improved by including inputs such as provided by the medial septum.

\section{References}

Almog Y, Brusel M, Anderson K, Rubinstein M (2019) Early hippocampal hyperexcitability followed by disinhibition in a mouse model of Dravet syndrome. bioRxiv. doi: https://doi.org/10.1101/790170.

Axmacher N, Henseler MM, Jensen O, Weinreich I, Elger CE, Fell J (2010) Cross-frequency coupling supports multi-item working memory in the human hippocampus. Proc Natl Acad Sci USA 107:3228-3233.

Bandarabadi M, Boyce R, Gutierrez Herrera C, Bassetti CL, Williams S, Schindler K, Adamantidis A (2019) Dynamic modulation of thetagamma coupling during rapid eye movement sleep. Sleep 42: zsz182.

Belluscio MA, Mizuseki K, Schmidt R, Kempter R, Buzsáki G (2012) Crossfrequency phase-phase coupling between $\theta$ and $\gamma$ oscillations in the hippocampus. J Neurosci 32:423-435.

Bender AC, Natola H, Ndong C, Holmes GL, Scott RC, Lenck-Santini PP (2013) Focal Scnla knockdown induces cognitive impairment without seizures. Neurobiol Dis 54:297-307.

Bender AC, Luikart BW, Lenck-Santini PP (2016) Cognitive deficits associated with Nav1.1 alterations: involvement of neuronal firing dynamics and oscillations. PLoS One 11:e0151538.

Bragin A, Jando G, Nadasdy Z, Hetke J, Wise K, Buzsaki G (1995) Gamma $(40-100 \mathrm{~Hz})$ oscillation in the hippocampus of the behaving rat. J Neurosci 15:47-60.

Bureau M, Dalla Bernardina B (2011) Electroencephalographic characteristics of Dravet syndrome. Epilepsia 52 [Suppl 2]:13-23.

Buzsáki G, Wang XJ (2012) Mechanisms of gamma oscillations. Annu Rev Neurosci 35:203-225.

Buzsáki G, Buhl DL, Harris KD, Csicsvari J, Czeh B, Morozov A (2003) Hippocampal network patterns of activity in the mouse. Neuroscience 116:201-211.

Cardin JA (2018) Inhibitory interneurons regulate temporal precision and correlations in cortical circuits. Trends Neurosci 41:689-700.

Cheah CS, Yu FH, Westenbroek RE, Kalume FK, Oakley JC, Potter GB, Rubenstein JL, Catterall WA (2012) Specific deletion of NaV1.1 sodium channels in inhibitory interneurons causes seizures and premature death in a mouse model of Dravet syndrome. Proc Natl Acad Sci USA 109:14646-14651.

Cossart R, Dinocourt C, Hirsch JC, Merchan-Perez A, De Felipe J, Ben-Ari Y, Esclapez M, Bernard C (2001) Dendritic but not somatic GABAergic inhibition is decreased in experimental epilepsy. Nat Neurosci 4:52-62.

Cressman JR Jr, Ullah G, Ziburkus J, Schiff SJ, Barreto E (2009) The influence of sodium and potassium dynamics on excitability, seizures, and the stability of persistent states: I. Single neuron dynamics. J Comput Neurosci 26:159-170.

Csicsvari J, Hirase H, Czurkó A, Mamiya A, Buzsáki G (1999) Oscillatory coupling of hippocampal pyramidal cells and interneurons in the behaving rat. J Neurosci 19:274-287.

De Stasi AM, Farisello P, Marcon I, Cavallari S, Forli A, Vecchia D, Losi G, Mantegazza M, Panzeri S, Carmignoto G, Bacci A, Fellin T (2016) Unaltered network activity and interneuronal firing during spontaneous cortical dynamics in vivo in a mouse model of severe myoclonic epilepsy of Iinfancy. Cereb Cortex 26:1778-1794. 
Deiana S, Watanabe A, Yamasaki Y, Amada N, Arthur M, Fleming S, Woodcock H, Dorward P, Pigliacampo B, Close S, Platt B, Riedel G (2012) Plasma and brain pharmacokinetic profile of cannabidiol (CBD), cannabidivarine (CBDV), $\Delta^{9}$-tetrahydrocannabivarin (THCV) and cannabigerol $(\mathrm{CBG})$ in rats and mice following oral and intraperitoneal administration and CBD action on obsessive-compulsive behaviour. Psychopharmacology (Berl) 219:859-873.

Devinsky O, Cross JH, Laux L, Marsh E, Miller I, Nabbout R, Scheffer IE, Thiele EA, Wright S; Cannabidiol in Dravet Syndrome Study G (2017) Trial of cannabidiol for drug-resistant seizures in the Dravet syndrome. N Engl J Med 376:2011-2020.

Dravet C (2011) The core Dravet syndrome phenotype. Epilepsia 52 [Suppl 2]:3-9.

Dugladze T, Vida I, Tort AB, Gross A, Otahal J, Heinemann U, Kopell NJ, Gloveli T (2007) Impaired hippocampal rhythmogenesis in a mouse model of mesial temporal lobe epilepsy. Proc Natl Acad Sci USA 104:17530-17535.

Dutton SBB, Dutt K, Papale LA, Helmers S, Goldin AL, Escayg A (2017) Early-life febrile seizures worsen adult phenotypes in Scnla mutants. Exp Neurol 293:159-171.

Favero M, Sotuyo NP, Lopez E, Kearney JA, Goldberg EM (2018) A transient developmental window of fast-spiking interneuron dysfunction in a mouse model of Dravet syndrome. J Neurosci 38:7912-7927.

Freund TF, Katona I (2007) Perisomatic inhibition. Neuron 56:33-42.

Gerbrandt LK, Lawrence JC, Eckardt MJ, Lloyd RL (1978) Origin of the neocortically monitored theta rhythm in the curarized rat. Electroencephalogr Clin Neurophysiol 45:454-467.

Goff KM, Goldberg EM (2019) Vasoactive intestinal peptide-expressing interneurons are impaired in a mouse model of Dravet syndrome. Elife 8.

Han S, Tai C, Westenbroek RE, Yu FH, Cheah CS, Potter GB, Rubenstein JL, Scheuer T, de la Iglesia HO, Catterall WA (2012) Autistic-like behaviour in Scnla $+/$ - mice and rescue by enhanced GABA-mediated neurotransmission. Nature 489:385-390.

Helmstaedter C, Elger CE (2009) Chronic temporal lobe epilepsy: a neurodevelopmental or progressively dementing disease? Brain 132:2822-2830.

Heusser AC, Poeppel D, Ezzyat Y, Davachi L (2016) Episodic sequence memory is supported by a theta-gamma phase code. Nat Neurosci 19:13741380.

Hübel N, Hosseini-Zare MS, Žiburkus J, Ullah G (2017) The role of glutamate in neuronal ion homeostasis: a case study of spreading depolarization. PLoS Comput Biol 13:e1005804.

Ittner AA, Gladbach A, Bertz J, Suh LS, Ittner LM (2014) p38 MAP kinasemediated NMDA receptor-dependent suppression of hippocampal hypersynchronicity in a mouse model of Alzheimer's disease. Acta Neuropathol Commun 2:149.

Jansen NA, Dehghani A, Breukel C, Tolner EA, van den Maagdenberg A (2020) Focal and generalized seizure activity after local hippocampal or cortical ablation of $\mathrm{NaV} 1.1$ channels in mice. Epilepsia 61:e30-e36.

Jefferys JG, Menendez de la Prida L, Wendling F, Bragin A, Avoli M, Timofeev I, Lopes da Silva FH (2012) Mechanisms of physiological and epileptic HFO generation. Prog Neurobiol 98:250-264.

Jiruska P, Finnerty GT, Powell AD, Lofti N, Cmejla R, Jefferys JG (2010) Epileptic high-frequency network activity in a model of non-lesional temporal lobe epilepsy. Brain 133:1380-1390.

Kalume F, Westenbroek RE, Cheah CS, Yu FH, Oakley JC, Scheuer T, Catterall WA (2013) Sudden unexpected death in a mouse model of Dravet syndrome. J Clin Invest 123:1798-1808.

Kalume F, Oakley JC, Westenbroek RE, Gile J, de la Iglesia HO, Scheuer T, Catterall WA (2015) Sleep impairment and reduced interneuron excitability in a mouse model of Dravet syndrome. Neurobiol Dis 77:141-154.

Kaplan JS, Stella N, Catterall WA, Westenbroek RE (2017) Cannabidiol attenuates seizures and social deficits in a mouse model of Dravet syndrome. Proc Natl Acad Sci USA 114:11229-11234.

Kilias A, Häussler U, Heining K, Froriep UP, Haas CA, Egert U (2018) Theta frequency decreases throughout the hippocampal formation in a focal epilepsy model. Hippocampus 28:375-391.

Kopell N, Börgers C, Pervouchine D, Malerba P, Tort A (2010) Gamma and theta rhythms in biophysical models of hippocampal circuits. In: Hippocampal microcircuits, pp 423-457. New York: Springer.

Liauard C, Scalmani P, Carriero G, de Curtis M, Franceschetti S, Mantegazza M (2013) Hippocampal hyperexcitability and specific epileptiform activity in a mouse model of Dravet syndrome. Epilepsia 54:1251-1261.

Lopez-Pigozzi D, Laurent F, Brotons-Mas JR, Valderrama M, Valero M, Fernandez-Lamo I, Cid E, Gomez-Dominguez D, Gal B, Menendez de la Prida L (2016) Altered oscillatory dynamics of CA1 parvalbumin basket cells during theta-gamma rhythmopathies of temporal lobe epilepsy. eNeuro 3: ENEURO.0284-16.2016.

Mistry AM, Thompson CH, Miller AR, Vanoye CG, George AL Jr, Kearney JA (2014) Strain- and age-dependent hippocampal neuron sodium currents correlate with epilepsy severity in Dravet syndrome mice. Neurobiol Dis 65:1-11.

Ogiwara I, Miyamoto H, Morita N, Atapour N, Mazaki E, Inoue I, Takeuchi T, Itohara S, Yanagawa Y, Obata K, Furuichi T, Hensch TK, Yamakawa K (2007) Nav1.1 localizes to axons of parvalbumin-positive inhibitory interneurons: a circuit basis for epileptic seizures in mice carrying an Scn la gene mutation. J Neurosci 27:5903-5914.

Papale LA, Makinson CD, Christopher Ehlen J, Tufik S, Decker MJ, Paul KN, Escayg A (2013) Altered sleep regulation in a mouse model of SCN1Aderived genetic epilepsy with febrile seizures plus (GEFS+). Epilepsia 54:625-634.

Racine RJ (1972) Modification of seizure activity by electrical stimulation. II. Motor seizure. Electroencephalogr Clin Neurophysiol 32:281-294.

Ray S, Maunsell JH (2011) Different origins of gamma rhythm and highgamma activity in macaque visual cortex. PLoS Biol 9:e1000610.

Rubinstein M, Westenbroek RE, Yu FH, Jones CJ, Scheuer T, Catterall WA (2015) Genetic background modulates impaired excitability of inhibitory neurons in a mouse model of Dravet syndrome. Neurobiol Dis 73:106117.

Sakkaki S, Barrière S, Bender AC, Scott RC, Lenck-Santini PP (2020) Focal dorsal hippocampal Nav1.1 knock down alters place cell temporal coordination and spatial behavior. Cereb Cortex 30:5049-5066.

Salgueiro-Pereira AR, Duprat F, Pousinha PA, Loucif A, Douchamps V, Regondi C, Ayrault M, Eugie M, Stunault MI, Escayg A, Goutagny R, Gnatkovsky V, Frassoni C, Marie H, Bethus I, Mantegazza M (2019) A two-hit story: seizures and genetic mutation interaction sets phenotype severity in SCN1A epilepsies. Neurobiol Dis 125:31-44.

Scheffzük C, Kukushka VI, Vyssotski AL, Draguhn A, Tort AB, Brankačk J (2011) Selective coupling between theta phase and neocortical fast gamma oscillations during REM-sleep in mice. PLoS One 6:e28489.

Schomburg EW, Fernández-Ruiz A, Mizuseki K, Berényi A, Anastassiou CA, Koch C, Buzsáki G (2014) Theta phase segregation of input-specific gamma patterns in entorhinal-hippocampal networks. Neuron 84:470485.

Shuman T, Amendolara B, Golshani P (2017) Theta rhythmopathy as a cause of cognitive disability in TLE. Epilepsy Curr 17:107-111.

Sirota A, Montgomery S, Fujisawa S, Isomura Y, Zugaro M, Buzsáki G (2008) Entrainment of neocortical neurons and gamma oscillations by the hippocampal theta rhythm. Neuron 60:683-697.

Stein RE, Kaplan JS, Li J, Catterall WA (2019) Hippocampal deletion of NaV1.1 channels in mice causes thermal seizures and cognitive deficit characteristic of Dravet syndrome. Proc Natl Acad Sci USA 116:1657116576.

Tai C, Abe Y, Westenbroek RE, Scheuer T, Catterall WA (2014) Impaired excitability of somatostatin- and parvalbumin-expressing cortical interneurons in a mouse model of Dravet syndrome. Proc Natl Acad Sci USA 111:E3139-E3148.

Takesian AE, Hensch TK (2013) Balancing plasticity/stability across brain development. Prog Brain Res 207:3-34.

Tort AB, Rotstein HG, Dugladze T, Gloveli T, Kopell NJ (2007) On the formation of gamma-coherent cell assemblies by oriens lacunosum-moleculare interneurons in the hippocampus. Proc Natl Acad Sci USA 104:13490-13495

Tort AB, Komorowski RW, Manns JR, Kopell NJ, Eichenbaum H (2009) Theta-gamma coupling increases during the learning of item-context associations. Proc Natl Acad Sci USA 106:20942-20947.

Tort AB, Komorowski R, Eichenbaum H, Kopell N (2010) Measuring phaseamplitude coupling between neuronal oscillations of different frequencies. J Neurophysiol 104:1195-1210.

Ullah G (2019) The role of transporters and synaptic cleft morphology in glutamate and GABA homeostasis and their effect on neuronal function. bioRxiv. doi: https://doi.org/10.1101/670844. 
Ullah G, Schiff SJ (2010) Assimilating seizure dynamics. PLoS Comput Biol 6:e1000776

Ullah G, Wei Y, Dahlem MA, Wechselberger M, Schiff SJ (2015) The role of cell volume in the dynamics of seizure, spreading depression, and anoxic depolarization. PLoS Comput Biol 11:e1004414.

Verret L, Mann EO, Hang GB, Barth AM, Cobos I, Ho K, Devidze N, Masliah E, Kreitzer AC, Mody I, Mucke L, Palop JJ (2012) Inhibitory interneuron deficit links altered network activity and cognitive dysfunction in Alzheimer model. Cell 149:708-721.

Vlooswijk MC, Jansen JF, de Krom MC, Majoie HM, Hofman PA, Backes WH, Aldenkamp AP (2010) Functional MRI in chronic epilepsy: associations with cognitive impairment. Lancet Neurol 9:1018-1027.

Wang XJ, Buzsáki G (1996) Gamma oscillation by synaptic inhibition in a hippocampal interneuronal network model. J Neurosci 16:64026413.

Wei Y, Ullah G, Schiff SJ (2014) Unification of neuronal spikes, seizures, and spreading depression. J Neurosci 34:11733-11743.

Wirrell EC, Laux L, Donner E, Jette N, Knupp K, Meskis MA, Miller I, Sullivan J, Welborn M, Berg AT (2017) Optimizing the diagnosis and management of Dravet syndrome: recommendations from a North American consensus panel. Pediatr Neurol 68:18-34.e3.

Wittner L, Eross L, Czirják S, Halász P, Freund TF, Maglóczky Z (2005) Surviving CA1 pyramidal cells receive intact perisomatic inhibitory input in the human epileptic hippocampus. Brain 128:138-152.

Wolff M, Cassé-Perrot C, Dravet C (2006) Severe myoclonic epilepsy of infants (Dravet syndrome): natural history and neuropsychological findings. Epilepsia 47 [Suppl 2]:45-48.

Wulff P, Ponomarenko AA, Bartos M, Korotkova TM, Fuchs EC, Bähner F, Both M, Tort AB, Kopell NJ, Wisden W, Monyer H (2009) Hippocampal theta rhythm and its coupling with gamma oscillations require fast inhibition onto parvalbumin-positive interneurons. Proc Natl Acad Sci USA 106:3561-3566

Yu FH, Mantegazza M, Westenbroek RE, Robbins CA, Kalume F, Burton KA, Spain WJ, McKnight GS, Scheuer T, Catterall WA (2006) Reduced sodium current in GABAergic interneurons in a mouse model of severe myoclonic epilepsy in infancy. Nat Neurosci 9:1142-1149.

Zhang X, Zhong W, Brankačk J, Weyer SW, Müller UC, Tort AB, Draguhn A (2016) Impaired theta-gamma coupling in APP-deficient mice. Sci Rep $6: 21948$ 